\title{
The Impact of Changes in Tropical Sea Surface Temperatures over 1979-2012 on Northern Hemisphere High-Latitude Climate
}

\author{
Michelle R. MCCRYSTALl ${ }^{\mathrm{a}}$ \\ British Antarctic Survey, and Department of Chemistry, University of Cambridge, Cambridge, United Kingdom \\ J. SCOTT HOSKING \\ British Antarctic Survey, Cambridge, United Kingdom \\ IAN P. WHITE \\ Earth Science Institute, Hebrew University of Jerusalem, Givat Ram, Jerusalem, Israel \\ AMANDA C. MAYCOCK \\ School of Earth and Environment, University of Leeds, Leeds, United Kingdom
}

(Manuscript received 21 June 2019, in final form 16 March 2020)

\begin{abstract}
While rapid changes in Arctic climate over recent decades are widely documented, the importance of different driving mechanisms is still debated. A previous study proposed a causal connection between recent tropical Pacific sea surface temperature (SST) trends and circulation changes over northern Canada and Greenland (NCG). Here, using the HadGEM3-A model, we perform a suite of sensitivity experiments to investigate the influence of tropical SSTs on winter atmospheric circulation over NCG. The experiments are forced with observed SST changes between an "early" (1979-88) and "late" period (2003-12) and applied across the entire tropics (TropSST), the tropical Pacific (PacSST), and the tropical Atlantic (AtlSST). In contrast to the previous study, all three experiments show a negative 200-hPa eddy geopotential height (Z200) anomaly over NCG in winter, which is similar to the response in AMIP experiments from four other climate models. The positive Z200 NCG anomaly in ERA-Interim between the two periods is inside the bounds of internal variability estimated from bootstrap sampling. The NCG circulation anomaly in the TropSST experiment is associated with a Rossby wave train originating from the tropical Pacific, with an important contribution coming from the tropical Atlantic SSTs connected via an atmospheric bridge through the tropical Pacific. This generates anomalous upper-level convergence and a positive Rossby wave source anomaly near the North Pacific jet exit region. Hence, while a tropics-Arctic teleconnection is evident, its influence on recent Arctic regional climate differs from observed changes and warrants further research.
\end{abstract}

\section{Introduction}

Arctic climate has undergone large and rapid changes over the last several decades (e.g., Hartmann et al. 2013). Surface air temperatures in the Arctic, especially in boreal autumn and winter months, have increased at around twice the rate of the global mean (Serreze et al.

\footnotetext{
${ }^{\text {a }}$ Current affiliation: University of Manitoba, Winnipeg, Manitoba, Canada.
}

Corresponding author: Michelle R. McCrystall, michelle. mccrystall@umanitoba.ca
2009; Screen and Simmonds 2010a; Lesins et al. 2012; Cohen et al. 2014; Gong et al. 2017). Increases in mid-toupper-tropospheric temperatures in the Arctic have also been found, although at a lesser rate than at the surface, as well as observed increases in precipitation, cloudiness, and storms (Kattsov and Walsh 2000; Graversen et al. 2008; Screen and Simmonds 2010b; Walsh et al. 2011; Screen et al. 2013; Ding et al. 2014).

Much of the observed change in Arctic climate has been attributed to increasing greenhouse gases and changes in anthropogenic aerosols (Bindoff et al. 2013; Chung and Räisänen 2011; Breider et al. 2017). However, uncertainty still exists regarding the driving mechanisms, with forcings 
from both local and remote regions being described as key mechanisms in the literature. Screen and Simmonds (2010a) argued that since the observed warming is greatest at the surface in boreal autumn and winter, changes in sea ice must be a primary driver, even though the greatest sea ice reductions have occurred in summer and early autumn (Serreze and Stroeve 2015). Screen et al. (2013) hypothesized that Arctic-wide sea ice reductions and Arctic surface temperatures were related through ice-albedo feedbacks. This occurs due to the loss of Arctic sea ice resulting in open water in the Arctic Ocean and thus a greater heat flux into the ocean in summer months (Screen and Simmonds 2010a; Bintanja and van der Linden 2013). This reverses in autumn and winter months, with a net upward heat flux resulting in surface warming (Screen and Simmonds 2010a; Serreze et al. 2009). Local radiative feedbacks associated with changing surface temperatures, water vapor, and clouds can also amplify Arctic warming (e.g., Pithan and Mauritsen 2014; Goosse et al. 2018).

Local processes are clearly of central importance for Arctic climate; however, there has been increasing attention on the influence of remote regions. In particular, changes in sea surface temperatures (SSTs) outside of the Arctic have been shown to be an important driver of Arctic warming (Tokinaga et al. 2017) both at the surface (Langen and Alexeev 2007) and in the middle and upper troposphere (Screen et al. 2013). In the atmosphere, the effects of remote SSTs on the Arctic are communicated through poleward transport of heat and moisture (Cai 2005; Graversen et al. 2008; Gimeno et al. 2015; Cao et al. 2017; Yoshimori et al. 2017; Chemke and Polvani 2020), which can increase local cloudiness, water vapor, and latent heat release (Graversen and Wang 2009; Bintanja et al. 2011), resulting in increased downward longwave radiation (Cao et al. 2017; Gong et al. 2017; Lee et al. 2017). Planetary-scale Rossby waves play a vital role in the horizontal transport of heat and moisture by the atmosphere (Graversen and Burtu 2016; Hoskins and Karoly 1981). Lee (2012) posited the tropically excited Arctic warming mechanism (TEAM), which proposes that on interannual time scales the changes to tropical convection associated with La Niña generates anomalous Rossby wave activity resulting in warming over the Arctic in boreal winter, and vice versa for El Niño. El Niño has also been found to affect summer circulation in northern high latitudes through generating precipitation and divergence anomalies in the tropical Pacific, which generate a Rossby wave to the North Atlantic and Eurasia (O'Reilly et al. 2019, 2018). Other modes of decadal climate variability, such as the interdecadal Pacific oscillation (IPO) and the Pacific decadal oscillation (PDO), have also been shown to alter the rate of Arctic warming. The negative phases of IPO and PDO have been found to result in more rapid Arctic warming (Meehl et al. 2018; Screen and Francis 2016), which may be the result of a poleward propagating wave train (Trenberth et al. 2014). However, the role of the PDO is somewhat disputed as Svendsen et al. (2018) suggest that the warming of the Arctic in the early twentieth century was associated with a positive phase of the PDO.

Although most studies have focused on the role of tropical Pacific teleconnections to the Arctic, some have also highlighted how tropical Atlantic variability can impact Arctic climate. In a modeling sensitivity study, Meehl et al. (2018) found that anomalous convection in the tropical Atlantic generated circulation anomalies over the Arctic in boreal summer, similar to those observed between 2000 and 2014. Both Atlantic and Pacific variability have been shown to be important for the atmospheric circulation patterns associated with the early twentieth-century warming in the Arctic (Tokinaga et al. 2017; Wegmann et al. 2017). In the mid-twentieth century, there was a period of Arctic cooling which was shown to be due to a transition to a negative phase of the Atlantic multidecadal oscillation between 1940 and 1970 (Chylek et al. 2009). Castruccio et al. (2019) also found that Atlantic multidecadal variability (more commonly used now to describe low-frequency Atlantic SST variations) has had a significant influence on modulating Arctic sea ice trends through changes to both ocean heat transport and atmospheric circulation. Mahajan et al. (2011) found, in a long control simulation, that an intensified Atlantic meridional overturning circulation results in increased surface air temperatures and reduced sea ice in the Arctic. A Rossby wave train generated in the tropical Atlantic was also found to result in warming over Svalbard (Flournoy et al. 2016). Distinguishing the relative importance of different tropical basins for climate trends in the Arctic is complicated by the challenge of separating the role of atmospheric and ocean processes, and the fact that tropical SST forcing in one basin can influence atmospheric circulation in other basins (Cai et al. 2019).

Most studies on tropical-Arctic teleconnections have tended to focus on the influence of remote regions on pan-Arctic climate; however, understanding regional polar change is important particularly in relation to sea ice loss and glacial melt. Understanding changes to the climate in northern Canada and Greenland (NCG) are specifically important as sea ice within the Canadian Archipelago is among the thickest in the Arctic and melting of the Greenland Ice Sheet is making a substantial contribution to global sea level rise (Shepherd et al. 2019). Screen and Simmonds (2010b) analyzed 
radiosonde data between 1998 and 2008 and found a temperature increase over the Canadian Arctic of $0.6^{\circ} \mathrm{C}$ linked to SST changes outside of the Arctic. Winter surface air temperatures have increased on the coastal edges of Greenland by $5.7^{\circ} \mathrm{C}$ between 1981 and 2012 (Hanna et al. 2014), which may lead to ice melt and destabilization of the ice sheet and thus have implications for future sea level rise. Ding et al. (2014, hereafter D14) analyzed reanalysis data and found a positive trend in annual mean upper tropospheric geopotential height over NCG between 1979 and 2012, which they identified as a driver of locally enhanced near-surface temperature trends. They found a similar trend in a general circulation model forced only with tropical SST trends over the same period and concluded that the local geopotential height and surface temperature trends were a consequence of tropical SST trends. They posited a mechanism related to a poleward propagating Rossby wave train emanating from the tropical Pacific (also Trenberth et al. 2014). While the reanalysis trends in wave activity flux (WAF) shown by D14 also indicate a poleward propagating wave train from the tropics toward NCG, there were differences in the wave propagation between the reanalysis data and the model results, therefore indicating that there is uncertainty in this mechanism.

This study aims to further examine the influence of recent tropical SST changes on atmospheric circulation over the NCG region during boreal winter [DecemberFebruary (DJF)]. We use climate model experiments in which observed SST changes are imposed in different tropical ocean basins. The experiments use prescribed SSTs and sea ice, which allows us to specifically distinguish the role of atmospheric processes from coupling with the ocean. We aim to build on recent work to further elucidate the mechanisms for tropical forcing of atmospheric circulation at high northern latitudes.

\section{Methods}

\section{a. Global atmospheric model}

We use the Hadley Centre Global Environmental Model version 3 in atmosphere-only mode (HadGEM3-A) at N96 horizontal resolution $\left(1.25^{\circ}\right.$ latitude $\times 1.875^{\circ}$ longitude, $\sim 130 \mathrm{~km}$ in the tropics) with 85 vertical levels extending to an altitude of $\sim 84 \mathrm{~km}$ (Hewitt et al. 2011). The model is forced with monthly mean SST and sea ice fields from the Hadley Centre Sea Ice and Sea Surface Temperature (HadISST) dataset, which incorporates both in situ and satellite measurements (Rayner et al. 2003).

\section{b. Sea surface temperature perturbations and experiment design}

The design of the perturbation experiments focuses on SST changes over the period 1979-2012 to coincide with the analysis of D14. Figure 1a shows the differences in annual mean SSTs between the "early" period (1979$88)$ and the "late" period (2003-12) in HadISST. The pattern shows a large-scale warming of SSTs across most of the Northern Hemisphere, with the main exception being parts of the tropical and North Pacific, which show cooling corresponding to a shift from a positive to a negative phase of the PDO (e.g., Kosaka and Xie 2013). As our focus is on the role of tropical SSTs for atmospheric circulation, we impose the observed differences in SSTs in the tropics between the early and late periods identified above (Fig. 1a), amplified by a factor of 2, and exclude extratropical changes as detailed below.

Four experiments are performed (see Table 1), each integrated for 60 years with the first 2 years discounted from the analysis to allow for spinup. The first experiment, CONTROL, is a reference state forced with global SSTs and sea ice from a 10-yr climatology over 1979-88 and with atmospheric greenhouse gas concentrations, aerosols, and solar forcing fixed at 1979-88 levels. There are therefore no external sources of interannual variability in CONTROL, only that which is produced internally by the atmosphere. The second experiment, hereafter referred to as TropSST, uses the same SSTs as CONTROL poleward of $31.25^{\circ} \mathrm{N} / \mathrm{S}$, but within the tropics the differences in monthly mean SSTs between the late (2003-12) and early (1979-88) periods, multiplied by a factor of 2 , are imposed (see Fig. 1b). The imposed SST anomalies are smoothed using a linear-weighted sine function between $20^{\circ}$ and $31.25^{\circ} \mathrm{N} / \mathrm{S}$ (Fig. 2b). This smoothing minimizes sharp gradients in SST across the tropical-extratropical boundary (Fig. 2a). The imposed SST anomalies exceed $1^{\circ} \mathrm{C}$ in the northern tropical Atlantic and southwest tropical Pacific (Fig. 1b). In the tropical east Pacific, the anomalies exceed $-1^{\circ} \mathrm{C}$ near the coast of South America. The two other model experiments are similar to TropSST, except that the anomalous SSTs are applied in either the tropical Pacific or tropical Atlantic basins only (PacSST and AtlSST, respectively) to separate the impacts of changes in SSTs in these sectors. We performed a separate experiment perturbing SSTs only in the Indian Ocean, but this was found to have negligible effect on the region of focus in this study and hence we do not include those results. The smoothing function used in the TropSST experiment is additionally applied along the coastlines of each tropical ocean basin in PacSST and AtlSST. Using an atmosphere-only model with fixed 

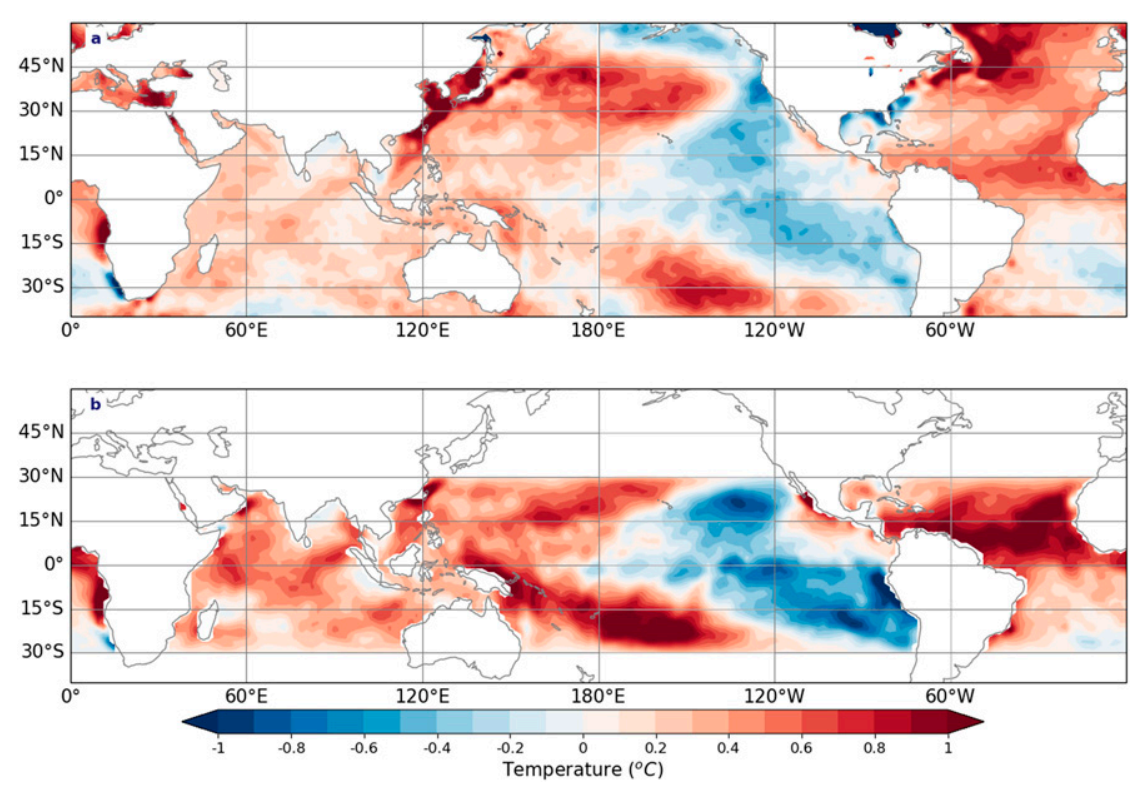

FIG. 1. (a) The difference in annual mean tropical SSTs $\left({ }^{\circ} \mathrm{C}\right)$ between the periods $2003-12$ and 1979-88 in HadISST and (b) the annual mean of the SST perturbation imposed in the TropSST experiment, where the anomalies are twice the amplitude of those in (a).

changes in SST means that we are able to isolate how the atmosphere responds to particular ocean surface anomalies. However, it does lack feedback processes associated with ocean-atmosphere interactions that would occur in a coupled model (Screen and Francis 2016).

To assess the response of the atmosphere to the tropical SST perturbations, we take the difference of the perturbation experiments (TropSST, PacSST, and AtISST) relative to CONTROL and assess the statistical significance of the results using a two-tailed Student's $t$ test. We also assess the changes between the late and early periods in the European Centre for MediumRange Weather Forecasts (ECMWF) interim reanalysis dataset (ERA-Interim; Dee et al. 2011) and compare these to AMIP experiments from four models generated through the Facility for Climate Assessment (FACTS) Experiments conducted by the NOAA Earth System Research Laboratory (ERSL) Physical Sciences
Division (PSD). The FACTS models used are ECHAM5, CAM4, GFS, and CAM5. These were run from 1979 to 2014 and forced with observed time-varying SSTs and sea ice concentrations (Hurrell et al. 2008), greenhouse gas concentrations, aerosols, and ozone from the AC\&C/SPARC ozone dataset (Cionni et al. 2011). The greenhouse gas concentrations follow the representative concentration pathway (RCP) 6.0 scenario from 2006 onward. The analysis focuses on DJF as this is when the largest changes in climate in the NCG region have been observed and when conditions are most favorable for poleward propagation of Rossby waves into the Northern Hemisphere (Hoskins and Karoly 1981; Trenberth et al. 1998; Lee 2012).

\section{c. Wave activity flux}

We use the wave activity flux (WAF) defined by Plumb (1985) to quantify the anomalous wave activity

TABLE 1. Details of model experiments with description of SSTs. All other boundary conditions (e.g., greenhouse gases, aerosols, and solar forcing) are held fixed at mean 1979-88 levels. Each experiment was run for 60 years.

\begin{tabular}{ll}
\hline \hline Model experiment & \multicolumn{1}{c}{ SST forcing } \\
\hline CONTROL & Global SST based on 10 -yr climatology from $1979-88$ \\
TropSST & $2 \times[(2003-12$ SSTs $)-(1979-88$ SSTs $)]$ between $32^{\circ} \mathrm{N}$ and $32^{\circ} \mathrm{S}$ \\
& CONTROL SSTs elsewhere \\
PacSST & $2 \times[(2003-12$ SSTs $)-(1979-88$ SSTs $)]$ between $32^{\circ} \mathrm{N}$ and $32^{\circ} \mathrm{S}$ within the tropical Pacific basin only \\
& CONTROL SSTs elsewhere \\
AtlSST & $2 \times[(2003-12$ SSTs $)-(1979-88$ SSTs $)]$ between $32^{\circ} \mathrm{N}$ and $32^{\circ} \mathrm{S}$ within the tropical Atlantic basin only \\
& CONTROL SSTs elsewhere \\
\hline
\end{tabular}



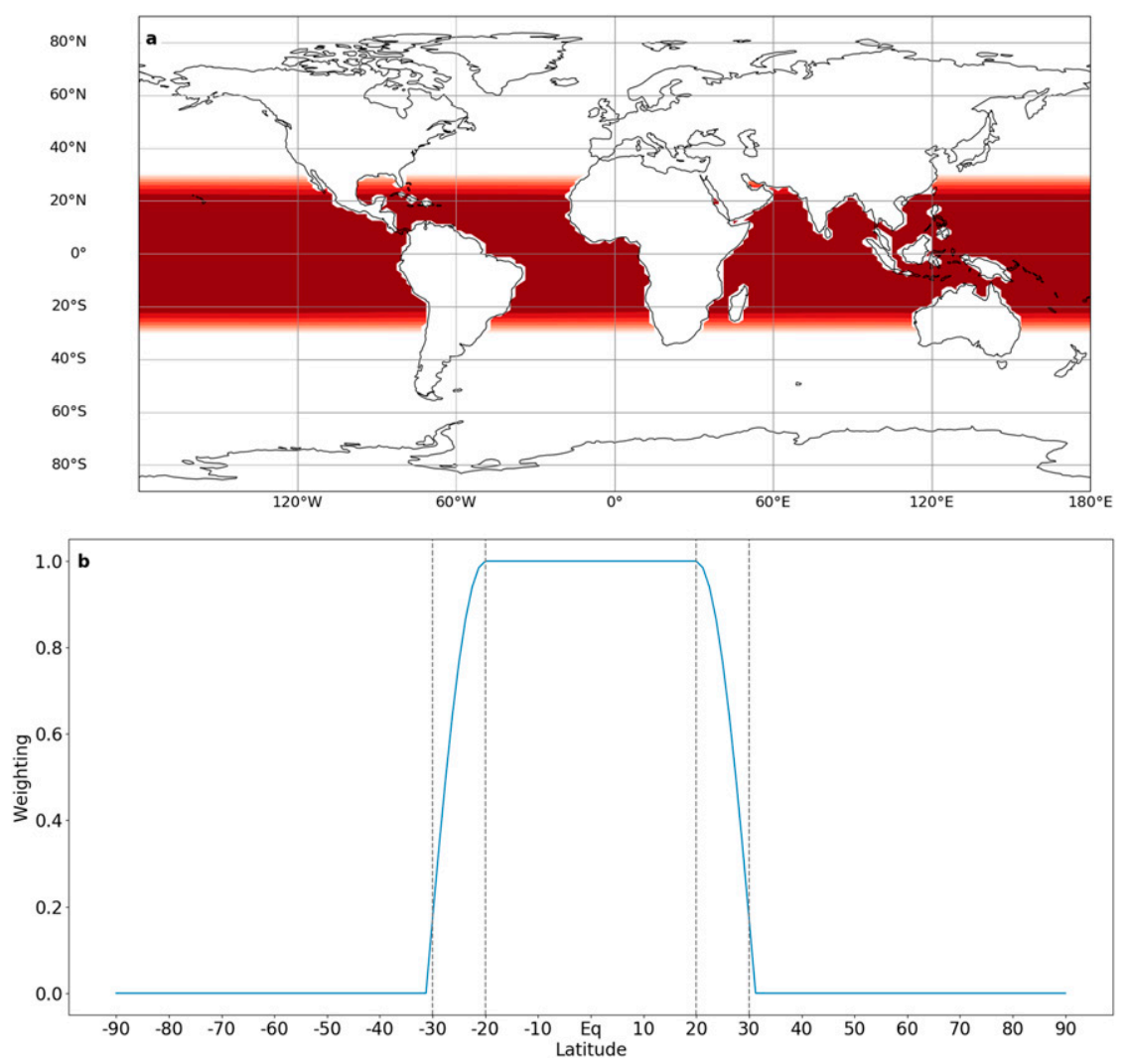

FIG. 2. (a) Weighting function for the SST forcing applied over the tropics with red indicating full forcing and white indicating no forcing. The scale from red to white along the tropical edges is a linear weighted sine function to smooth the tropical SST anomalies onto the background climatological state with a weighting of 1 between $\pm 20^{\circ}$ latitude and decreasing to 0 by $\pm 32^{\circ}$.

resulting from the imposed tropical SST perturbations. As this study is primarily concerned with horizontal wave propagation, we use the $2 \mathrm{D}$ horizontal $\mathrm{WAF}, \mathbf{F}_{s}$ :

$$
\mathbf{F}_{s}=p \cos \phi\left[\begin{array}{c}
v^{\prime 2}-\frac{1}{2 \Omega a \sin 2 \phi} \frac{\partial\left(v^{\prime} \Phi^{\prime}\right)}{\partial \lambda} \\
-u^{\prime} v^{\prime}+\frac{1}{2 \Omega a \sin 2 \phi} \frac{\partial\left(u^{\prime} \Phi^{\prime}\right)}{\partial \lambda}
\end{array}\right],
$$

where $u$ and $v$ are the zonal and meridional wind, $\Phi$ is geopotential height, $p$ is pressure $1000 \mathrm{mb}, \Omega$ is Earth's rotation rate, $a$ is Earth's radius, and $\phi$ and $\lambda$ are latitude and longitude, respectively. Primes denote the deviation from the zonal mean. The value of $\mathbf{F}_{s}$ was calculated using monthly mean fields and then averaged over DJF.

\section{d. Rossby wave source}

Following Sardeshmukh and Hoskins (1988), the Rossby wave source derived from the barotropic vorticity equation is given by

$$
S=-\mathbf{v}_{\chi} \cdot \nabla \zeta-\zeta D=-\nabla \cdot\left(\mathbf{v}_{\chi} \zeta\right)
$$

where $\zeta$ is the absolute vorticity, $D$ is the divergence of the horizontal wind, and $\mathbf{v}_{\chi}$ is the divergent component of the horizontal wind. The first term on the right-hand side of the middle equality in Eq. (2) $\left(-\mathbf{v}_{\chi} \cdot \nabla \zeta\right)$ relates to the advection of vorticity by the divergent wind. The second term $(-\zeta D)$ relates to the generation of vorticity by vortex stretching. The RWS is large in areas of large gradients of absolute vorticity and divergent wind (O'Kane et al. 2016). Shimizu and de Albuquerque Cavalcanti (2010) state that these conditions exist along the jet streams or poleward of diabatic heating, where the divergent component of wind is greater due to convection and where there are large background gradients of vorticity. In the Northern Hemisphere, negative (positive) values of the RWS indicate anticyclonic (cyclonic) vorticity sources and consequently divergence (convergence).

\section{Results}

\section{a. Reanalysis data and FACTS simulations}

Figure 3 shows 200-hPa eddy geopotential height (Z200) fields in DJF from ERA-Interim, with contours 


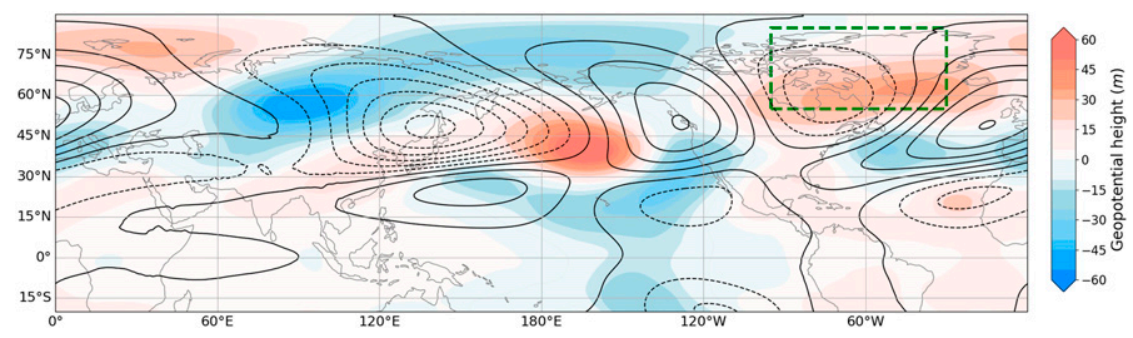

FIG. 3. Shading shows differences in boreal winter (DJF) eddy geopotential height at $200 \mathrm{hPa}$ (Z200) (m) in ERA-Interim between the 10-yr periods 2003-12 and 1979-88. The contours show the DJF climatology over 1979-88 with a contour spacing of $50 \mathrm{~m}$. The green box denotes the northern Canada and Greenland (NCG) region, which is the primary focus of this study.

showing the average over the early period (1979-88) and shading showing differences between the late and early periods. Over the NCG region, highlighted by the green box, there is a positive eddy Z200 anomaly of up to $40 \mathrm{~m}$, which indicates weakening of the climatological trough in this region shown in the contours. While this behavior is broadly consistent with the annual mean trends in eddy Z200 over NCG found by D14, there are some differences in the pattern over the Pacific compared to D14. D14 showed an apparent wave train emanating from the central tropical Pacific and propagating across North America (see also Trenberth et al. 2014), which was identified from a maximum covariance analysis as the second mode of the covariance between tropical SSTs and Z200. Instead, Fig. 3 shows a cyclone pair straddling the equator in the central Pacific, which is reminiscent of a Gill-Matsuno-type response to anomalous tropical heating (Gill 1980), and a weakening of the Aleutian low, but less evidence of a wave train connecting the tropical Pacific and NCG region.

To determine the forced change in circulation over NCG, we examine AMIP model simulations generated through the FACTS project (see section 2). The four models analyzed from this dataset-ECHAM5, CAM4, ESRL-GFSv2, and ERSL-CAM5-each provide 30, 20, 30 , and 20 ensemble members, respectively, differing only in their atmospheric initial conditions. Figure 4 shows the ensemble mean differences in eddy Z200 between 1979-88 and 2003-12 in the four AMIP models. All the models simulate a highly consistent pattern of eddy Z200 differences in the Northern Hemisphere. There is a consistent decrease in geopotential height over northern Canada, albeit with some variation in magnitude (CAM4 shows the largest change and ESRLGFSv2 the weakest). The differences in eddy Z200 in the tropical Pacific are also similar in the models, with a pair of cyclonic anomalies straddling the equator and an anticyclonic anomaly in the North Pacific around the Aleutian Islands. While the eddy Z200 patterns in the tropics are similar to ERA-Interim (Fig. 3), the differences over NCG, in particular over Canada, have the opposite sign. This suggests that the differences in ERAInterim may be the result of internal atmospheric variability (Fig. 7) and the forced response associated with

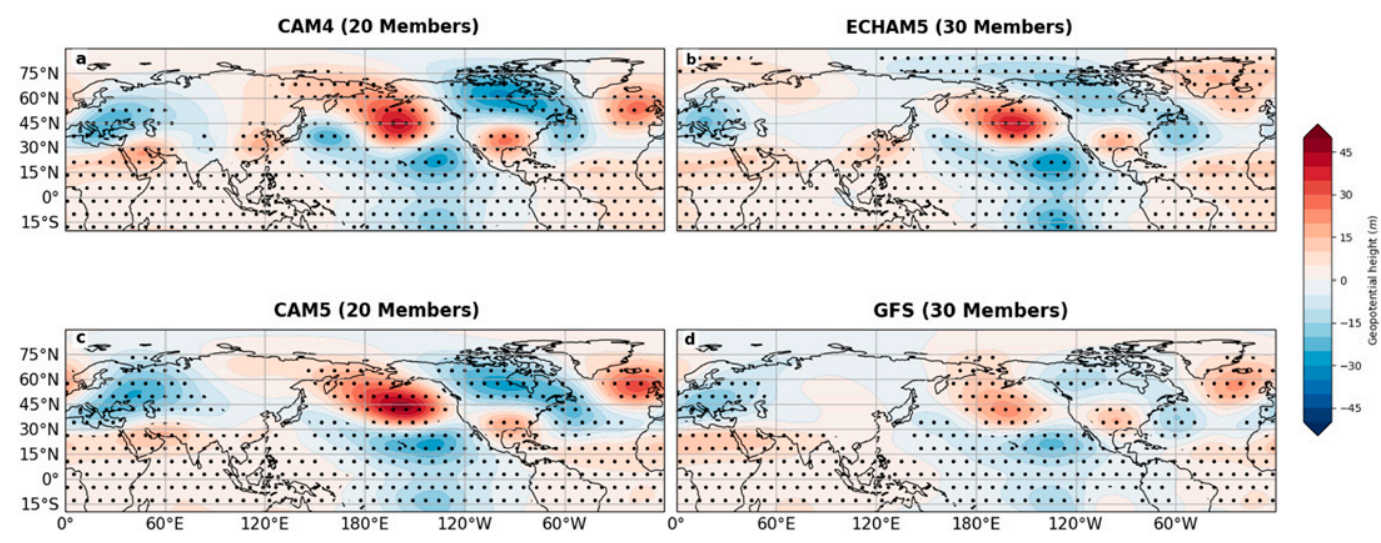

FIG. 4. The ensemble mean difference in DJF eddy Z200 (m) between 1979-88 and 2003-12 in the AMIP simulations from (a) CAM4, (b) ECHAM5, (c) ESRL-CAM5, and (d) ESRL-GFDv2. The number of ensemble members for each model is given in the header. Stippling denotes regions where the differences are statistically significant at the $95 \%$ confidence level. 


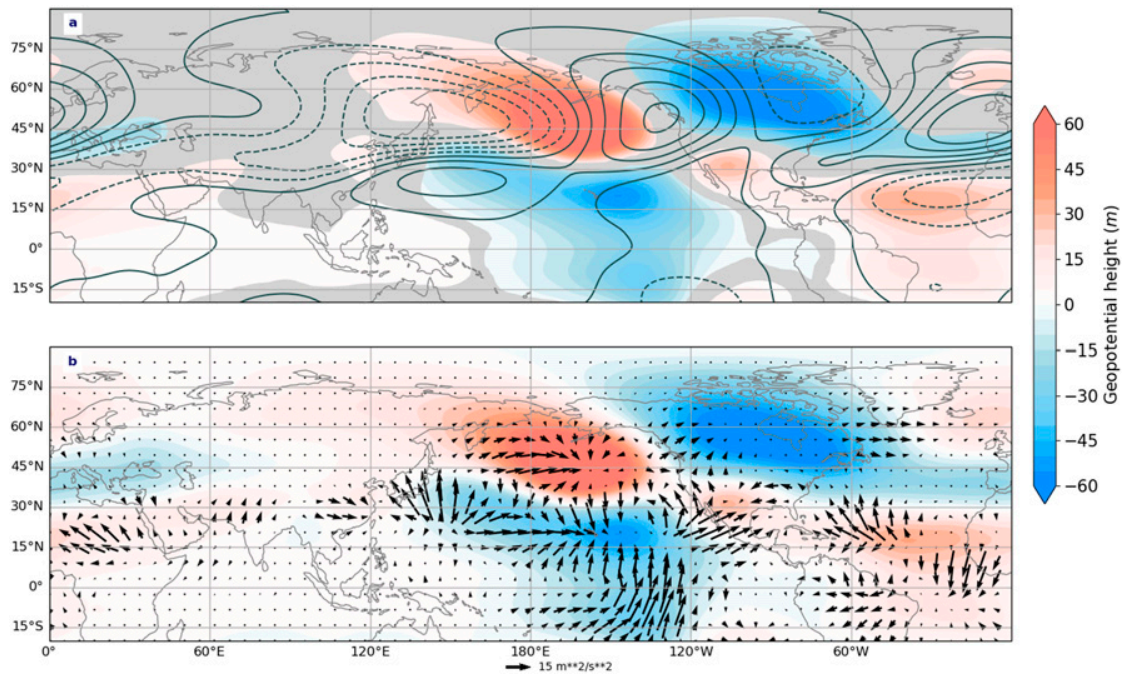

FIG. 5. The difference in DJF eddy Z200 (m) between the TropSST and CONTROL experiments. The gray shading in (a) denotes regions where the differences are not statistically significant at the $95 \%$ confidence level and the contours show the CONTROL climatology with intervals at every $50 \mathrm{~m}$. Dashed contours denote negative values. The vectors overlaid in (b) denote the differences in 200-hPa wave activity flux $\left(\mathrm{m}^{2} \mathrm{~s}^{-2}\right)$.

globally changing SSTs and greenhouse gases is associated with a cyclonic anomaly over NCG.

\section{b. Response in TropSST experiment}

The shading in Fig. 5a shows the eddy Z200 anomalies in DJF in the TropSST experiment. A large statistically significant negative eddy Z200 anomaly is found over most of Canada and the northern United States extending into the North Atlantic, representing a deepening of the climatological trough in that region (contours in Fig. 5a). This is in contrast to the changes found in the reanalysis data (Fig. 3), which has a positive eddy Z200 anomaly over NCG and larger changes over Greenland than found in the TropSST experiment, despite the fact the imposed tropical SSTs are double the observed differences. The TropSST response is, however, similar to the differences in eddy Z200 in the FACTS experiments (Fig. 4), thus highlighting a role for changes in tropical SSTs in driving this high-latitude pattern. Furthermore, the simulated pattern in TropSST bears some similarity to the streamfunction anomaly found over northern Canada by Meehl et al. (2018) when forcing the CAM3 model with convective anomalies in the tropical Pacific associated with a negative phase of the IPO. This suggests a potential role for decadal variability in determining this pattern. Statistically significant eddy Z200 anomalies are found in the tropical Atlantic and Pacific basins, which are generally consistent with the results from the reanalysis dataset. In both tropical ocean basins, the anomalous eddy Z200 patterns peak in the northern subtropics with a decrease in the central Pacific and an increase in the Atlantic. Positive eddy Z200 anomalies in the North Pacific correspond to a weakening of the Aleutian low, which is consistent with the effect of tropical Pacific cooling on the Aleutian low found in earlier studies (Niebauer 1988; Rodionov et al. 2007; Sheridan and Lee 2012; Ding et al. 2018). In contrast to the findings of D14, our experiments show that the mean changes in tropical SSTs between 1979-88 and 2003-12 cannot explain the observed eddy Z200 trends over NCG. This may be a consequence of (i) the analysis of seasonal changes rather than annual trends; (ii) the experiment design using timeslice experiments rather than transient forcings (however, the similarity of the TropSST response to the FACTS AMIP experiments suggests this is not a major factor); (iii) the use of another climate model to D14 that produces different tropical-extratropical teleconnections; or (iv) differences in internal variability and its influence on tropical-extratropical teleconnections between the model and reanalysis. To test (i) we examined the annual mean differences in eddy Z200 between TropSST and CONTROL; this showed a similar pattern to the DJF differences with a negative eddy Z200 anomaly over northern Canada that is weaker but still statistically significant at the $95 \%$ confidence level (not shown). We therefore conclude that the focus on boreal winter in this study compared to the annual mean analysis of D14 cannot explain the difference in sign of the response over NCG. Point (iv) is investigated in section 3d. 

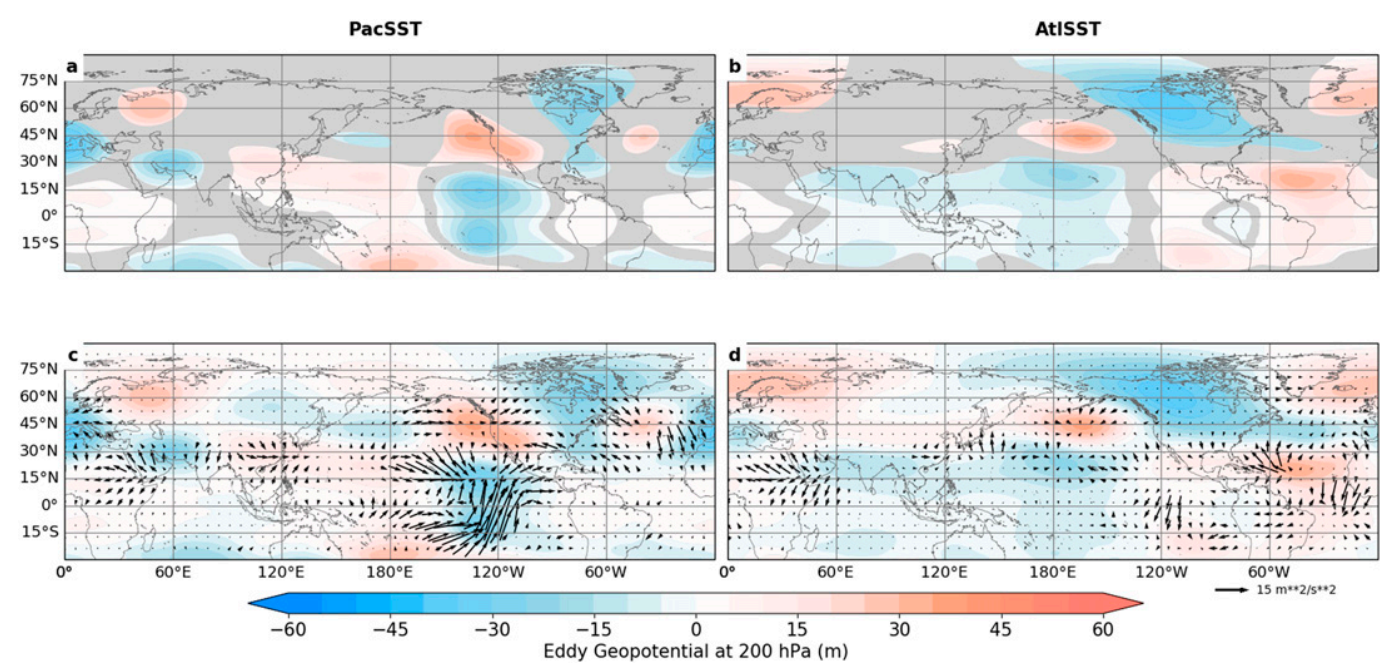

FIG. 6. Differences in DJF eddy Z200 (m) in the (a),(c) PacSST and (b),(d) AtlSST experiments. The gray shading in (a) and (b) denotes regions where the differences are not statistically significant at the $95 \%$ confidence level. Vectors in (c) and (d) show the 200-hPa wave activity flux $\left(\mathrm{m}^{2} \mathrm{~s}^{-2}\right)$ responses.

In relation to point (iii), we examine the changes in wave propagation connected to the eddy Z200 response in the TropSST experiment. The vectors in Fig. 5b show anomalies in $200 \mathrm{hPa} \mathrm{WAF}$ [see Eq. (1)]. This shows the imposed SST changes generate anomalous wave activity in the tropical west Pacific $\left(20^{\circ}-30^{\circ} \mathrm{N}\right)$ over the western edge of the region of negative eddy Z200 (shading in Fig. 5b, with WAF in vectors). This anomalous WAF shows propagation poleward and eastward where it appears to divide, with a wave train propagating equatorward around $160^{\circ} \mathrm{W}$, and another continuing to propagate over North America into NCG and toward the North Atlantic. This indicates that the circulation response over NCG in TropSST is the result of a poleward propagating wave train excited in the tropical Pacific and propagating northeastward across the North Pacific. This wave train broadly agrees with that in the ERA-Interim trends shown by D14, but not with the findings from their model simulations.

The results of TropSST demonstrate that changes to WAF in both the Atlantic and Pacific basins may be important for the simulated circulation response in the NCG region. To further understand and separate the relative roles of SST changes in the two ocean basins, the next section analyses further HadGEM3-A experiments in which the SST perturbations are applied in only the Pacific or Atlantic basins.

\section{c. Responses in PacSST and AtlSST experiments}

As described in section $2 b$, the SST perturbations applied in the PacSST and AtlSST experiments are identical to those in TropSST except applied only in the tropical Pacific and tropical Atlantic basins, respectively. The responses of eddy Z200 and WAF for the PacSST and AtISST experiments are shown in Fig. 6, which can be compared to the TropSST response in Fig. 5. Both experiments show a negative eddy Z200 anomaly over NCG, which resembles the change seen in TropSST. However, this feature has a deeper minimum and shows a greater westward extension in the AtISST experiment, while in the PacSST experiment it is weaker and confined to northeast Canada and Greenland. However, when considering the NCG area average Z200 anomaly, the two experiments are largely indistinguishable (see section $3 \mathrm{~d}$ ).

Both the PacSST and AtlSST experiments show statistically significant eddy Z200 anomalies in the tropical Pacific and Atlantic sectors, but these are weaker than in the TropSST experiment. In PacSST, there are eddy Z200 anomalies of alternating sign in the Pacific Ocean indicating a tropical-extratropical wave train. This wave train, also identifiable in the WAF (Fig. 6c), emanates from the tropical west Pacific around $175^{\circ} \mathrm{E}, 20^{\circ} \mathrm{N}$ and propagates in an arc-like trajectory from the tropical Pacific over NCG, and equatorward into the North Atlantic. This resembles the response in the TropSST experiment, except that the wave train extends farther downstream in PacSST. The AtlSST experiment also has eddy Z200 anomalies within the tropical Pacific and Atlantic basins which, based on the WAF in the tropical Atlantic (Fig. 6d), are related to a wave train generated around $20^{\circ} \mathrm{N}$, which propagates poleward across the North Atlantic to Iceland and the Greenland Sea. These anomalies are similar to those in Elsbury et al. (2019), 
who forced a model with SST anomalies associated with the Atlantic multidecadal oscillation. Some WAF anomaly vectors in the tropical Atlantic are oriented westward, which indicates a reduction in the (generally eastward) climatological wave flux. Interestingly, despite there being no SST forcing in the Pacific Ocean in the AtISST experiment, there is still anomalous wave activity found in the extratropical Pacific. Figure $6 \mathrm{~d}$ shows anomalous wave generation around $30^{\circ} \mathrm{N}, 135^{\circ} \mathrm{E}$, which propagates across the North Pacific to a positive eddy $\mathrm{Z} 200$ anomaly around $60^{\circ} \mathrm{N}, 170^{\circ} \mathrm{W}$. This indicates that tropical Atlantic SST perturbations can play an important role in driving atmospheric dynamics in the Pacific basin, likely through changes in upper-level divergence (Kucharski et al. 2014; Simpkins et al. 2014; Chikamoto et al. 2016). This will be investigated further in section $3 \mathrm{e}$.

The results show that tropically excited Rossby waves forced by the imposed tropical SST anomalies generate remote circulation anomalies over the NCG region. Interestingly, the experiments indicate that the tropical Atlantic plays a significant role in driving the circulation response over NCG in TropSST. While these findings are in contrast to some other studies (Lau and Nath 1994; Ding et al. 2011; Ferranti et al. 1994; Ding et al. 2014; Trenberth et al. 2014), several recent studies have highlighted the importance of tropical Atlantic SSTs for high-latitude teleconnections in Northern Hemisphere summer (Meehl et al. 2018) and the Southern Hemisphere (Simpkins et al. 2012, 2014; Li et al. 2015).

The similarity between the change in circulation over the NCG region in our tropical SST forcing experiments and the FACTS AMIP simulations (Fig. 4), which account for all known forcings including extratropical SSTs and sea ice changes, suggests that tropical SST changes play an important role in the FACTS simulated responses. Nevertheless, the modeled responses are distinct from the differences in ERA-Interim shown in Fig. 3. This suggests that another factor such as internal variability may have contributed to the observed circulation changes in the NCG region. This is addressed in the following section.

\section{d. Role of internal variability}

To investigate the potential role of internal variability in determining the differences in circulation over NCG in ERA-Interim, we perform a bootstrap analysis (sampled $n=1000$ times) of differences in eddy Z200 between two random 10-yr samples with replacement from all ERA-Interim years. The distribution of eddy Z200 differences over NCG from these samples is shown in Fig. 7. The observed difference in ERA-Interim between the late (2003-12) and early (1979-88) periods

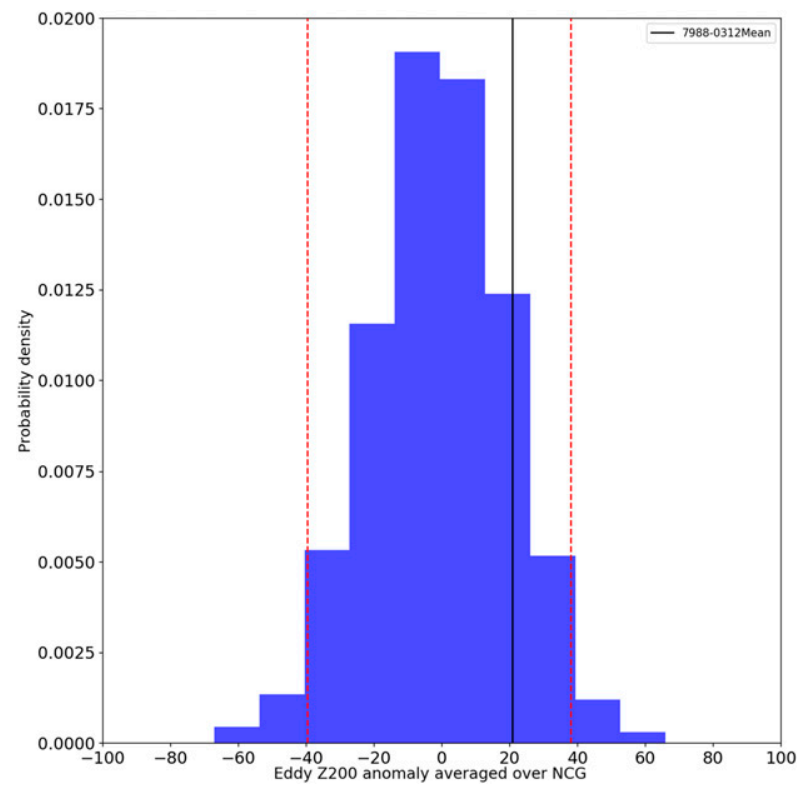

FIG. 7. Histogram of 1000-member bootstrap distribution for the difference in 10-yr random samples of DJF eddy Z200 over NCG in ERA-Interim between 1979 and 2014. The black solid line represents the mean difference between 1979-88 and 2003-12 and the red dashed lines represent the 2.5 th and 97.5 th percentiles.

(black line) lies inside the 95\% confidence interval estimated from the bootstrap samples, indicating the anomalous eddy Z200 over NCG is not highly significant compared to internal variability.

We now put the difference in circulation anomalies over NCG between ERA-Interim (Fig. 3) and the model simulations (Figs. 5 and 6) into the context of sampling uncertainty by performing a bootstrap analysis with replacement (sampled $n=1000$ times) of the model experiments. For the CONTROL experiment, differences are calculated between two 10-year random samples. For the perturbation experiments, we draw random 10 -yr samples from the perturbation experiment and CONTROL and then compute the difference in eddy Z200 over NCG. Figure 8 shows histograms of the bootstrap distributions of the eddy Z200 differences in each experiment. The 2.5th and 97.5th percentiles are shown in red lines to denote the $95 \%$ confidence interval and the black line is the difference from ERA-Interim between 1979-88 and 2003-12.

Figure 8a shows that in CONTROL there is substantial internal variability in the winter circulation over NCG and the difference diagnosed in ERA-Interim lies inside the sampling uncertainty of the model's internal variability alone (i.e., with no difference in SST). The bootstrap distribution of the TropSST experiment (Fig. 8b) shows a comparable spread to CONTROL centered around the long-term mean difference of 

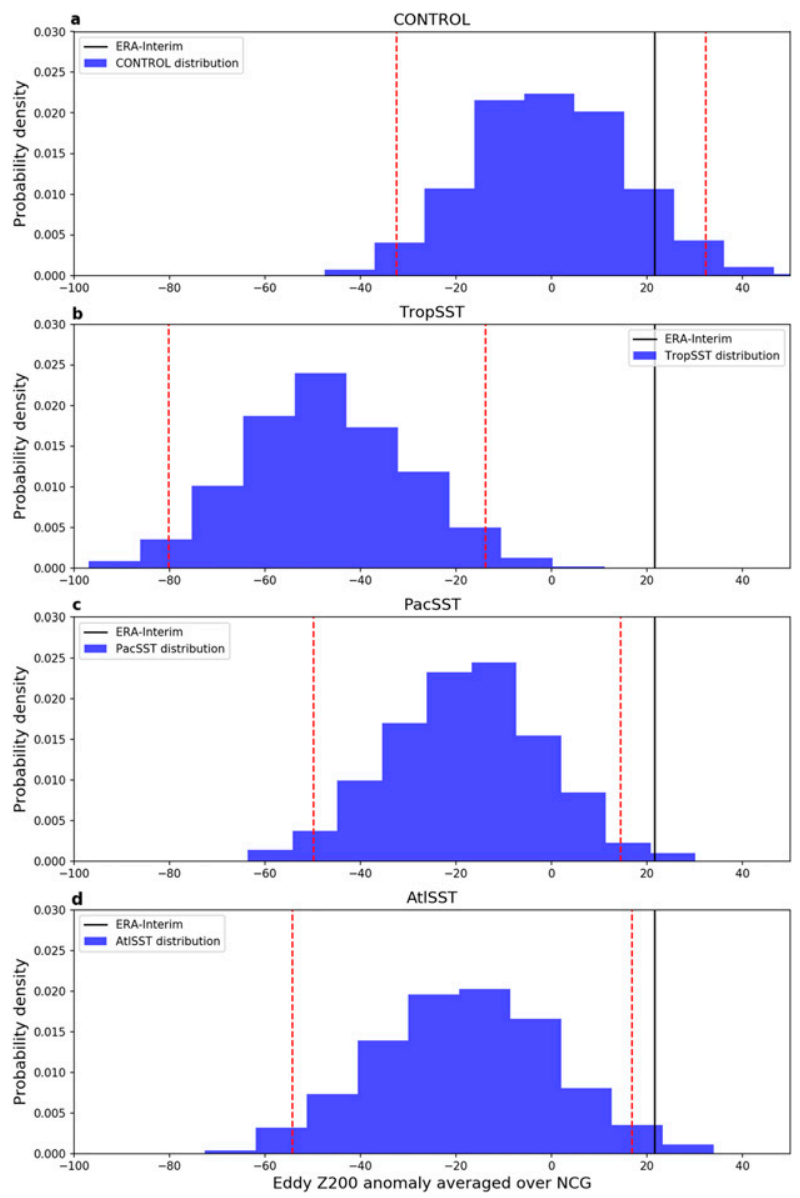

FIG. 8. Histograms of 1000-member bootstrap distributions for the difference in 10-yr random samples of DJF eddy Z200 over NCG in (a) CONTROL and for the responses in (b) TropSST, (c) PacSST, and (d) AtlSST relative to CONTROL. The black solid line represents the mean difference in ERA-Interim between 1979-88 and 2003-12 and the red dashed lines represent the 2.5th and 97.5 th percentiles.

around $-50 \mathrm{~m}$. The $95 \%$ confidence interval only spans negative values, showing it is extremely unlikely to find a positive eddy Z200 anomaly over NCG with the doubled tropical SST anomaly imposed. The anomaly from ERA-Interim is in the very upper tail of the TropSST distribution. Given the weaker responses in the AtISST and PacSST experiments (Figs. 8c,d), the observed ERA-Interim anomaly is proportionately more likely to occur in the context of those distributions, though in both cases the reanalysis anomaly lies outside of the $95 \%$ confidence intervals. These results indicate 1) that the observed differences were exceptional insofar as an anomaly of that magnitude was very unlikely to occur; 2 ) that the observed anomaly was forced by a factor other than tropical SST changes that is not accounted for in our experiments (though since the ensemble mean
FACTS experiments show a similar response to TropSST this seems unlikely to be the main explanation); 3) that there is some structural difference between the model and real world that makes the modeled distributions biased relative to observations; or 4) that the representation of interval variability in the model is different from the real world. It is virtually impossible to test most of these hypotheses; however, to address the fourth point we note that the spread in the bootstrap distribution of random 10-yr samples from ERAInterim is broadly comparable with CONTROL, albeit the distribution is slightly narrower in the model which might be expected given that CONTROL has fixed boundary conditions.

\section{e. Dynamical changes to the background flow}

To further investigate the mechanisms for the wave train response to the imposed tropical SST perturbations described in section $3 \mathrm{c}$, we now examine the underlying dynamical processes including the Rossby wave source and changes in background flow in the experiments.

Figure 9 shows the climatological 200-hPa (a) divergence and (b) Rossby wave source (RWS) in the CONTROL experiment, and Figs. 10a-f show the associated anomalies in the three SST perturbation experiments. As expected, the main divergence anomalies occur over the tropical oceans as the SST perturbations alter tropical convection (Figs. 10a-c). In the TropSST experiment, there is a region of enhanced divergence around the equator in the tropical Atlantic sector flanked by regions of enhanced convergence (Fig. 10a). This indicates a strengthening of convection in the tropical Atlantic and comes mainly from the local SST warming (Fig. 10c). In the tropical Pacific, the region of climatological divergence in the west Pacific associated with the intertropical convergence zone (ITCZ; see Fig. 9a) is significantly reduced in TropSST (Fig. 10a). The weakened divergence in the main branch of the ITCZ north of the equator and the anomalous convergence over the southeast United States are mainly driven by the local Pacific SST changes (Fig. 10b). However, in AtlSST there are also weaker but statistically significant changes in divergence in the Pacific sector. These show enhanced divergence in the main ITCZ band north of the equator and anomalous convergence to the south. In AtlSST there is also a region of anomalous divergence in the equatorial east Pacific which corresponds to a weakening of the climatological convergence there (Fig. 9a) and regions of anomalous divergence and convergence in the North Pacific. This indicates there is interbasin coupling between the Atlantic and Pacific that communicates the Atlantic SST 

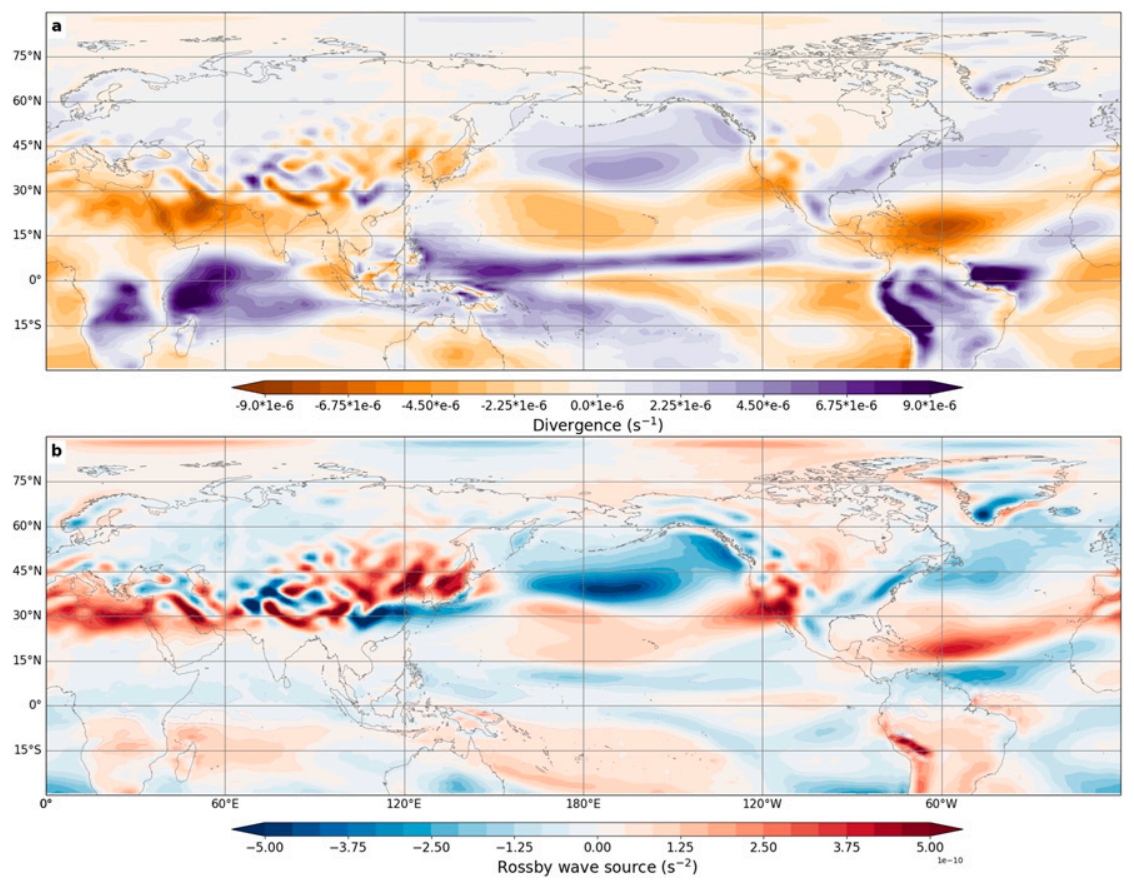

FIG. 9. Boreal winter (DJF) climatologies of 200-hPa (a) divergence $\left(\mathrm{s}^{-1}\right.$ ) and (b) Rossby wave source $\left(\mathrm{s}^{-2}\right)$ from the CONTROL experiment.

warming into the Pacific basin through atmospheric circulation (cf. Simpkins et al. 2014; McGregor et al. 2014; Li et al. 2015; Elsbury et al. 2019; Sutton and Hodson 2007; Sun et al. 2017; Davini et al. 2015; Okumura et al. 2009; Peings and Magnusdottir 2014).

To further illustrate this, Fig. 11 shows the longitudinal cross section of absolute zonal wind and vertical velocity vectors averaged between $10^{\circ} \mathrm{N}$ and $10^{\circ} \mathrm{S}$ in CONTROL (Fig. 11a) and the anomalous vectors in the TropSST, PacSST, and AtISST experiments (Figs. 11b-d). In CONTROL there is ascent in the tropical Atlantic sector between around $40^{\circ}-70^{\circ} \mathrm{W}$ and in the tropical west Pacific between $120^{\circ} \mathrm{E}-180^{\circ}$. Between these regions of ascent are regions of descent, such as in the central tropical Pacific and eastern tropical Atlantic, which close the Walker circulation. In both the TropSST and AtlSST experiments (Figs. 11b,d), there is a strengthening of the ascent in the tropical Atlantic sector relative to CONTROL. In AtISST there is westward flow at upper levels from the Atlantic into the Pacific sector and anomalous descent around $130^{\circ} \mathrm{W}$ and between $160^{\circ} \mathrm{E}$ and $180^{\circ}$. In contrast, in the PacSST experiment the changes in overturning circulation are largely confined to the Pacific sector. This highlights that the Atlantic SST perturbation results in a strengthening of the upper-level flow between the Atlantic and Pacific basins, inducing changes in upper-level divergence as seen in Fig. 10c.
Given the evidence for an important role of both Pacific and Atlantic SSTs for the RWS response in the TropSST experiment, we also examine the relative linearity of the PacSST and AtlSST responses relative to TropSST. Figure 12 shows the sum of the PacSST + AtlSST responses for (a) divergence anomalies and (b) RWS anomalies. The patterns of the combined PacSST + AtISST responses are very similar to the TropSST experiment (Figs. 10a,d). For example, the east-west dipole anomalies of divergence and RWS across the extratropical Pacific are present. However, although the sum of the anomalies shows the same sign as in Figs. 10a and 10d, the differences are generally weaker than in the TropSST experiment. This could be due to a weakening of the SST anomalies along the coastlines in the PacSST and AtISST experiments that is not included in the TropSST experiment (see section 2b). Another explanation is that the differences between the anomalies are due to nonlinear interbasin interactions between the tropical Pacific and Atlantic circulations (Simpkins et al. 2014; Li et al. 2015).

Next we investigate the changes in RWS in boreal winter, shown for the three SST perturbation experiments in Figs. 10d-f. We find that these closely resemble the patterns found in the divergence anomalies, suggesting that changes to upper-level divergence are an important driver of the RWS responses. To test this, we examine the relative contributions of the two terms in 

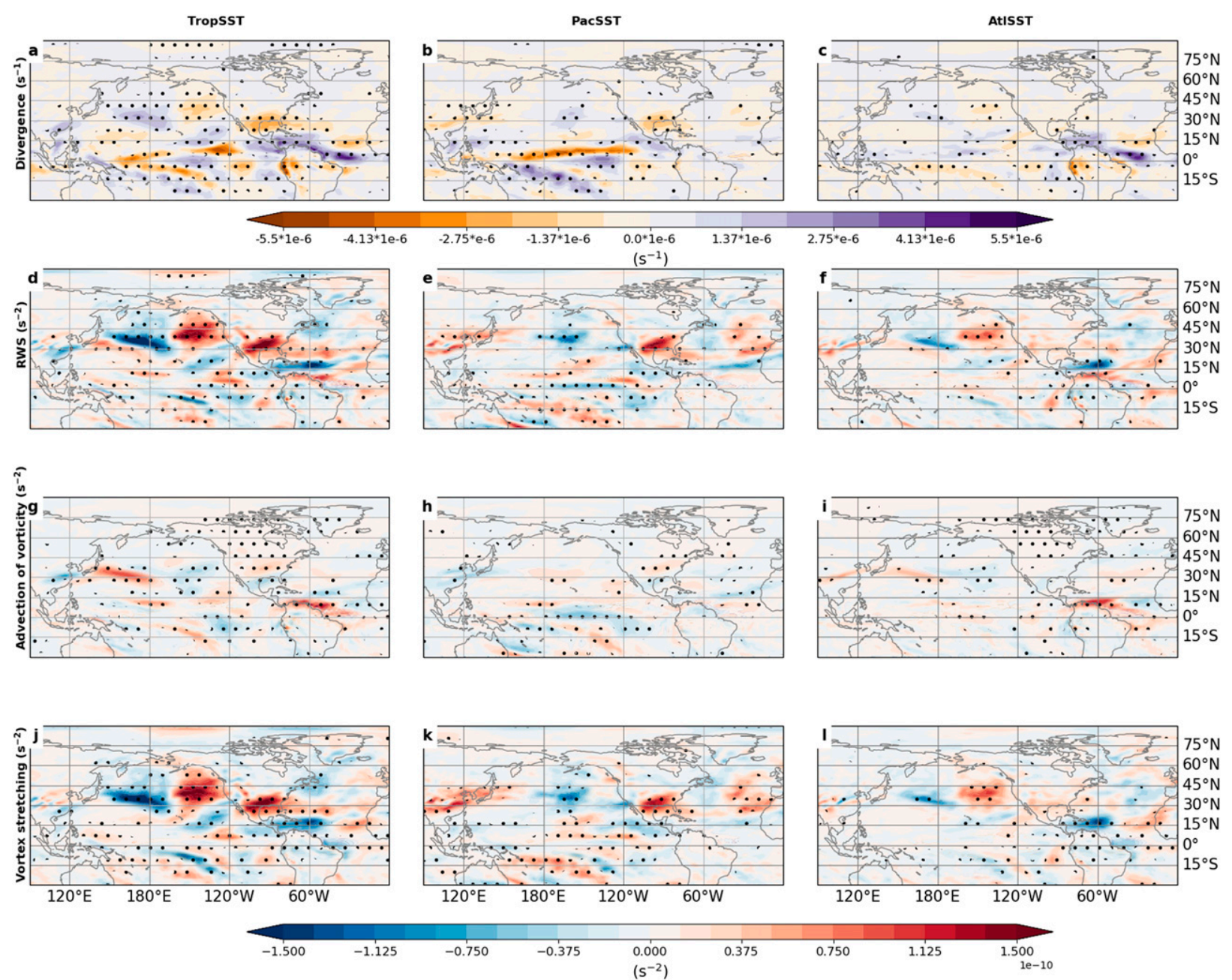

FIG. 10. Difference in boreal winter (DJF) 200-hPa (a)-(c) divergence $\left(\mathrm{s}^{-1}\right)$, (d)-(f) Rossby wave source (RWS) ( $\left.\mathrm{s}^{-2}\right)$, (g)-(i) vortex stretching term $\left(\mathrm{s}^{-2}\right)$, and (j)-(l) advection of absolute vorticity term $\left(\mathrm{s}^{-2}\right)$ for the (a), (d), (g),(j) TropSST, (b), (e),(h),(k) PacSST, and (c),(f),(i),(l) AtlSST experiments relative to the CONTROL experiment. Stippling denotes regions where differences are statistically significant at the $95 \%$ confidence level.

Eq. (2) to the RWS, which represent vorticity advection by the divergent component of the wind (Figs. 10g-i) and vortex stretching, or the generation of vorticity by divergence (Freitas and Ambrizzi 2012) (Figs. 10j-1). Comparing the two terms to the total RWS anomalies in Figs. 10d-f, the vortex stretching term generally dominates in the extratropics, consistent with the findings of Tyrrell et al. (1996) and Freitas and Ambrizzi (2012), while both vorticity advection and vortex stretching contribute to the anomalous RWS in the tropics (Jin and Hoskins 1995). This highlights that it is unsurprising to have similar divergence and RWS anomalies.

We now examine the spatial patterns of the RWS anomalies. Figure 10d shows a meridional tripole pattern of RWS anomalies in the western tropical Atlantic between around $5^{\circ}$ and $35^{\circ} \mathrm{N}$, which comes mainly from the Atlantic SST forcing (Fig. 10f). In PacSST, there is a negative RWS anomaly in the central equatorial Pacific flanked by positive anomalies to the north and south. While the largest divergence anomalies are found in the tropics, collocated with the anomalous SSTs, the strongest RWS anomalies are found in the extratropical North Pacific owing to the larger absolute vorticity and vorticity gradients in the vicinity of the North Pacific jet (Shimizu and de Albuquerque Cavalcanti 2010). The enhanced divergence near $30^{\circ}-45^{\circ} \mathrm{N}, 180^{\circ}$ and decreased divergence in the northeast Pacific at $45^{\circ} \mathrm{N}, 130^{\circ} \mathrm{W}$ in TropSST and AtlSST (Figs. 10a,c) are coincident with strong RWS anomalies, with regions of anomalous divergence (convergence) corresponding to regions of negative (positive) RWS anomalies (Figs. 10d,f). This can be contrasted with the enhanced divergence in the 
(a) CONTROL

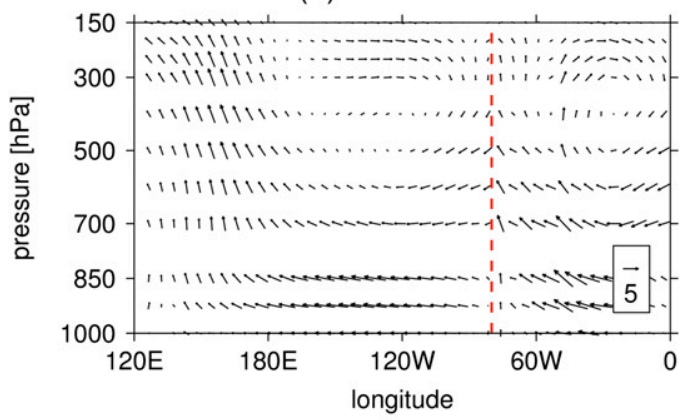

(c) PacSST

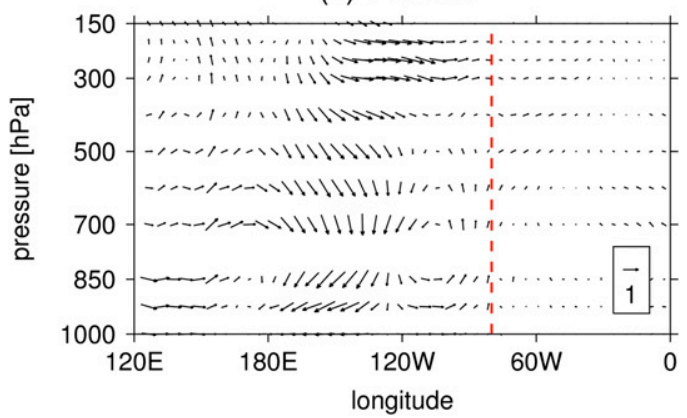

(b) TropSST

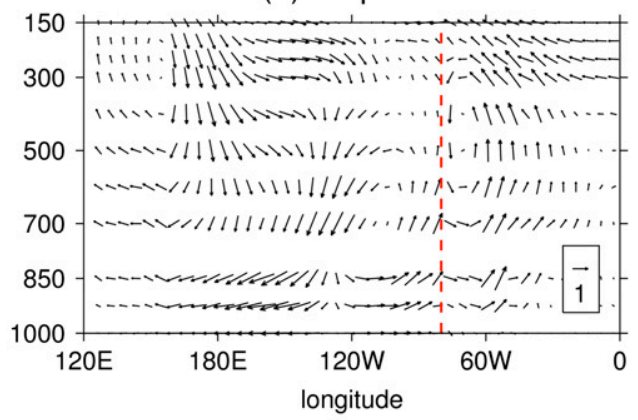

(d) AtISST

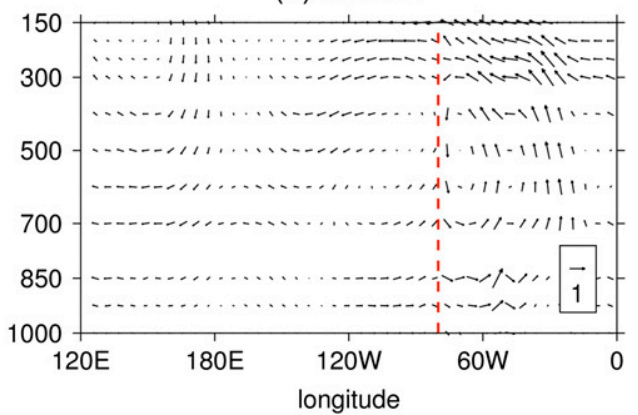

FIG. 11. Zonal and vertical wind vectors $\left(\mathrm{m} \mathrm{s}^{-1}\right)$ in DJF averaged over $\pm 10^{\circ}$ latitude in the Pacific and Atlantic sectors. (a) CONTROL climatology, and differences in (b) TropSST, (c) PacSST, and (d) AtlSST. Red line approximately demarcates the Pacific and Atlantic sectors. The zonal wind is scaled by a factor $(p / 1000)$ and the vertical wind by a factor $p$ for plotting.

North Pacific near $30^{\circ} \mathrm{N}, 170^{\circ} \mathrm{W}$ in PacSST and a negative RWS anomaly, indicating an enhanced anticyclonic vorticity tendency.

Jin and Hoskins (1995) and Freitas et al. (2017) found that anomalous divergence (convergence) coincident with negative (positive) RWS anomalies result in anticyclonic (cyclonic) circulation near the source and wavelike structures downstream. We find a similar result when comparing the anomalous RWS (Figs. 10d-f) with the eddy Z200 anomalies in Fig. 5a (TropSST) and Figs. $6 \mathrm{a}$ and $6 \mathrm{~b}$ (PacSST and AtlSST, respectively). In the extratropical North Pacific, downstream of the negative RWS anomaly between $135^{\circ} \mathrm{E}$ and $170^{\circ} \mathrm{W}$ and around $40^{\circ} \mathrm{N}$, which is mostly driven by vortex stretching (Freitas et al. 2017), there is a positive eddy Z200 anomaly and downstream of the positive RWS anomaly, a negative eddy Z200 anomaly. Therefore, as TropSST and AtlSST have similar RWS and divergence anomalies in the North Pacific, it is expected that their circulation responses would be similar and therefore explains the similarity in the response of NCG circulation in the two experiments. This highlights that the North Pacific response in TropSST is strongly influenced by the Atlantic SST anomalies, which then acts to amplify the negative NCG anomaly driven by the tropical Pacific SSTs.
Various studies have found a remote influence of Atlantic warming on the North Pacific (e.g., Elsbury et al. 2019; Davini et al. 2015; Sutton and Hodson 2007; Zhang and Delworth 2007; Okumura et al. 2009; Sun et al. 2017; Ruprich-Robert et al. 2017; Kucharski et al. 2014; Zhang et al. 2019), particularly in the context of Atlantic multidecadal variability (AMV). Several of these studies show a weakening of the Aleutian low and a trough over North America due to imposed warming in the tropical Atlantic, which is similar to the response in the AtlSST experiment. Some of these studies used coupled models and found that Atlantic warming produces east Pacific cooling through modulation of the Walker circulation (e.g., McGregor et al. 2014; Ruprich-Robert et al. 2017; Kucharski et al. 2014); this means the North Pacific response may be partly mediated through tropical Pacific ocean-atmosphere coupling that is neglected in our experiments. Kucharski et al. (2014) performed an experiment using an atmospheric model with imposed Atlantic warming and showed anomalous low-level westerlies in the tropical east Pacific and tropical Atlantic and enhanced lowlevel easterlies in the tropical west Pacific (see their Fig. 3c); this resembles the pattern of lower tropospheric equatorial zonal winds in AtlSST (Fig. 11). Furthermore, Ruprich-Robert et al. (2017) performed an experiment 

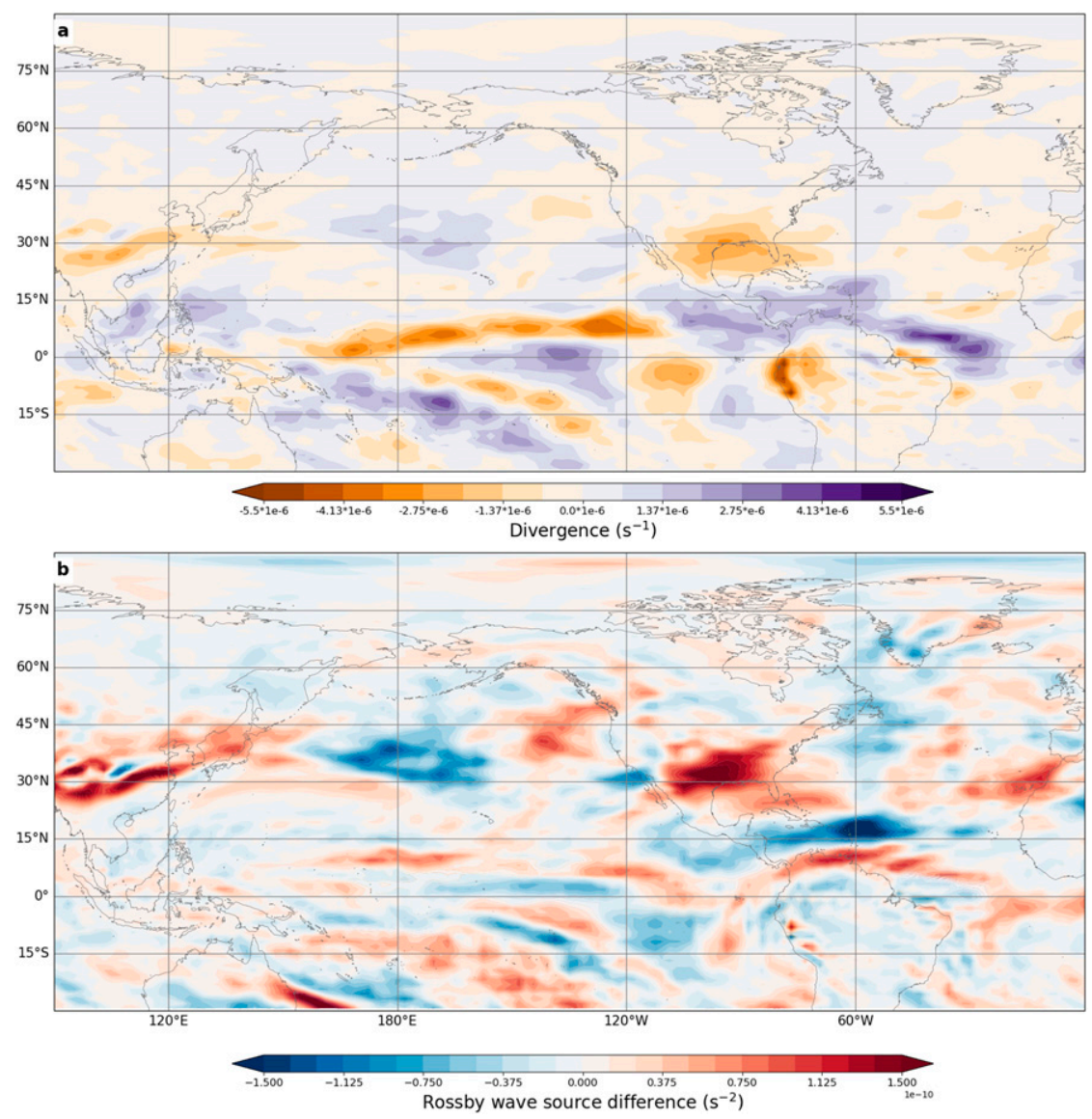

FIG. 12. The sum of the PacSST and AtISST anomalies in 200-hPa (a) divergence $\left(\mathrm{s}^{-1}\right)$ and (b) RWS $\left(\mathrm{s}^{-2}\right)$.

using CESM1 with imposed tropical Atlantic warming and with tropical Pacific SSTs relaxed toward climatology, thereby removing the Pacific-SST feedback. The experiment also showed a weakening of the Aleutian low and a trough over North America (see their Fig. 9f), albeit with a weaker magnitude than when the PacificSST feedback is included. The extratropical Rossby wave pattern in their experiment closely resembles the response in AtlSST. The findings of Ruprich-Robert et al. (2017) along with our results show an atmospheric bridge connects tropical Atlantic warming with a weakened Aleutian low (Figs. 5 and 6) is mediated through the perturbed Walker circulation and ITCZ shown in Figs. 11 and 10c. This remote response to Atlantic warming amplifies the Pacific-driven negative eddy Z200 response over NCG.

\section{f. Comparison with ERA-Interim}

To put the dynamical analysis into the context of the reanalysis data, we compare the modeled response in divergence and WAF to the differences in ERA-Interim between 1979-88 and 2003-12 (Fig. 13). Differences in divergence are plotted where they are statistically significant at the $95 \%$ level computed from a 1000 -member bootstrap distribution of differences between two 10-yr random samples from ERA-Interim.

The ERA-Interim differences show a negative divergence anomaly in the northern subtropical Pacific to the east of the date line. There is also a similar feature in the Atlantic sector to the east of the Caribbean Sea. Both of these regions of anomalies are broadly consistent with the TropSST experiment, but they are generally less spatially coherent and the signal-to-noise lower in this short period. The WAF anomalies in ERA-Interim show comparable differences to the TropSST experiment in the northern subtropical Pacific, with poleward wave energy fluxes in the western Pacific and equatorward fluxes in the eastern Pacific. However, the WAF anomalies over North America and into the NCG region have an opposite direction in ERA-Interim to the TropSST experiment, which is likely associated with the difference in sign of the geopotential height anomalies 


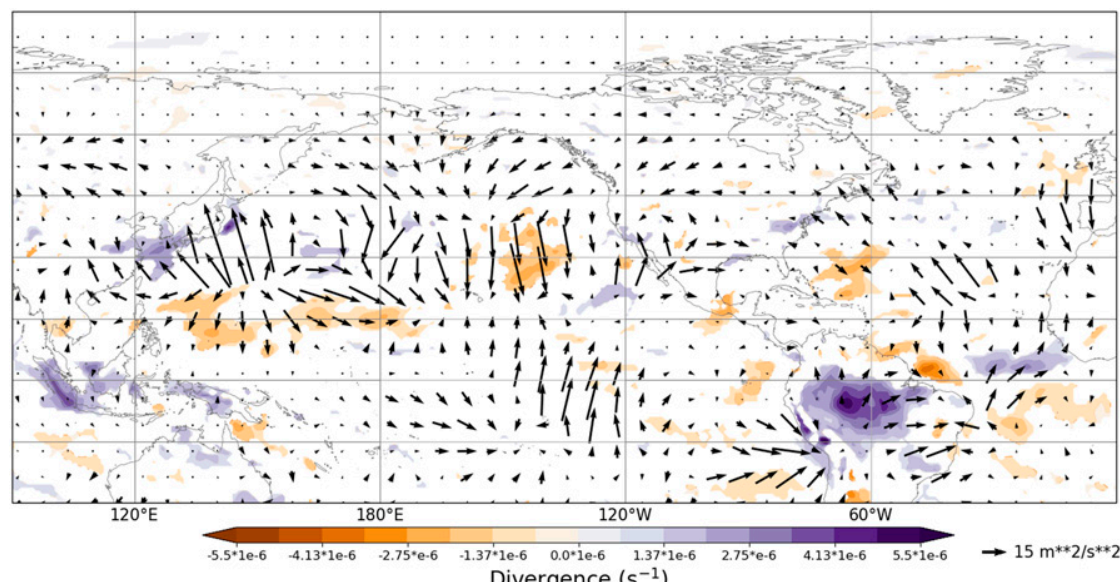

Divergence $\left(\mathrm{s}^{-1}\right)$

FIG. 13. Differences in 200-hPa divergence ( $\mathrm{s}^{-1}$; shading) and WAF $\left(\mathrm{m}^{2} \mathrm{~s}^{-2}\right.$; vectors) between 1979-88 and 2003-12 in the ERA-Interim reanalysis. Only areas where the difference in divergence is statistically significant at the $95 \%$ confidence level are shown. Confidence intervals are estimated from a 1000-member bootstrap distribution of differences between two random 10-yr periods in ERA-Interim.

over NCG between ERA-Interim and the model experiments. The overall low significance of the ERAInterim anomalies provides further motivation for performing long model simulations with a doubledamplitude SST forcing, so the effect of changes in SSTs can be distinguished from internal variability.

\section{Discussion}

Our study was motivated by D14, who performed trend analysis over 1979 to 2012 and found a positive trend in annual mean eddy Z200 over NCG, which they linked to an anomalous Rossby wave train emanating from the eastern tropical Pacific. In this study, however, we find an opposite response to anomalous tropical SST perturbations derived from the same period imposed in a global atmospheric model. Our time slice experiments forced with anomalous SSTs between $30^{\circ} \mathrm{N}$ and $30^{\circ} \mathrm{S}$ (TropSST) and in the Pacific and Atlantic Ocean basins only (PacSST and AtlSST, respectively), show a negative anomaly in boreal winter (DJF) 200-hPa eddy geopotential height over NCG. This result is supported by analysis of AMIP large initial condition ensemble experiments from four other models. Similarly to D14, we do find that the response to the imposed SSTs is associated with anomalous Rossby wave activity, but with a different structure and with an important role for the SST perturbations in the tropical Atlantic.

As discussed above, after excluding some possibilities, the differences in results between the two studies may be a consequence of the following:
1) The source region for the wave train in our experiments being located farther west in the subtropical Pacific (around $35^{\circ} \mathrm{N}, 130^{\circ} \mathrm{E}$ ) and propagating in an arc-like trajectory across the North Pacific, over NCG and into the North Atlantic. We have shown that the anomalous RWS is strongly related to the anomalous upper-level divergence, which will be related to the convective response to the imposed SSTs and this may differ between models.

2) Rossby wave propagation is sensitive to the background state (Scaife et al. 2017) and biases in the model's climatology compared to observations could affect wave propagation to high latitudes. In this version of HadGEM3, the subtropical jet in the Pacific sector is located farther poleward compared to the reanalysis and shows a northward tilt near the jet exit region (not shown). Therefore it is possible these differences would affect wave propagation from the tropical Pacific toward the Arctic. However, given that our results are in broad agreement with Meehl et al. (2018), who used the CAM5 model, and with the FACTS AMIP experiments, the main conclusions do not appear to be particularly sensitive to this.

3) Differences in experimental design between the studies. Here we use time slice model experiments with prescribed fixed SSTs and sea ice, while D14 use model experiments with prescribed time-varying SSTs in the tropics coupled to a slab ocean in the extratropics with a thermodynamic sea ice component. These additional factors may have played a role in differences between the responses, with feedbacks 
and coupling through changes in extratropical SSTs and sea ice potentially influencing the response over NCG. The FACTS AMIP simulations also prescribe SSTs and sea ice so they exclude twoway atmosphere-ocean coupling.

4) The representation of the stratosphere, which can play a prominent role in teleconnections between the tropical Pacific and high latitudes (e.g., Ineson and Scaife 2009; Trascasa-Castro et al. 2019). The model used here extends to $\sim 84-\mathrm{km}$ altitude whereas D14 used a model with relatively coarse vertical resolution. While analysis of the stratospheric response in these experiments is beyond the scope of this study, it is one factor that could influence the extratropical responses and warrants investigation in future.

The contrasting results of our study compared to D14 indicate that the role of teleconnections for atmospheric circulation over NCG is still uncertain. A further issue, which has implications for understanding tropicalextratropical teleconnections, is that current coupled climate models such as CMIP5 do not capture the correct SST gradient in the Pacific as observed thereby affecting their simulated tropical-extratropical teleconnections (Coats and Karnauskas 2017). This leads to further uncertainty in diagnosing tropical-extratropical teleconnections and their impacts on Arctic climate.

\section{Conclusions}

Identifying and separating the physical processes driving Arctic climate change is challenging due to the presence of large internal variability, nonlinear interactions between the atmosphere, oceans, and sea ice, and the relatively short observational record. This study examines the role of recent tropical sea surface temperature (SST) changes for atmospheric circulation over northern Canada and Greenland (NCG) using a set of experiments with the HadGEM3-A model. A control simulation (CONTROL) was forced with observed SSTs and sea ice averaged over 1979-88 and was compared to three perturbation experiments which include the addition of tropical SST anomalies from the period 2003-12. These anomalies were doubled in amplitude to increase the signal-to-noise ratio and were applied over the entire tropics (TropSST; $30^{\circ} \mathrm{N}-30^{\circ} \mathrm{S}$ ), in the tropical Pacific only (PacSST), and in the tropical Atlantic only (AtlSST).

All the experiments show a decrease in eddy geopotential height over NCG, which is opposite to the increase found in ERA-Interim between 1979-88 and 2003-12. The decadal mean difference in geopotential height over NCG in ERA-Interim was not found to be highly statistically significant based on a bootstrap analysis, but we note that the linear trend analysis of D14 did identify a significant positive trend in eddy geopotential height over NCG during this period. The signal of a decrease in eddy geopotential height over NCG was also found in a set of large initial condition ensemble AMIP experiments from four other models, lending confidence to the result from HadGEM3-A. The similar changes in circulation over NCG in the TropSST experiment and the AMIP simulations also suggest that tropical SST changes play a key role for the overall forced change in Northern Hemisphere circulation over this period. There is therefore disagreement between our results and D14 with respect to the role of recent multidecadal tropical SST changes in driving circulation changes over NCG. It is possible that the NCG circulation changes found by D14 were a result of coupled atmosphere-ocean interactions and feedbacks, which were excluded in HadGEM3-A and the FACTS simulations, but this remains to be tested.

The regional NCG response in the TropSST experiment was shown to be a consequence of both tropical Pacific and Atlantic SST changes. The response to the tropical Atlantic SSTs arises indirectly from the formation of an anomalous RWS in the extratropical Pacific mediated through interbasin coupling. Analysis of the vertical velocity and wind response indicates that warmer Atlantic SSTs drive westward equatorial upper-level flow between the Atlantic and Pacific, altering the Walker circulation and ITCZ position (cf. Elsbury et al. 2019; Sun et al. 2017). The anomalous upper-level divergence and RWS in the extratropical Pacific result in downstream wave propagation (Jin and Hoskins 1995). This, coupled with the poleward propagating wave train generated by the tropical Pacific SST anomalies, results in an amplification of the negative eddy Z200 anomaly over NCG relative to the PacSST experiment.

While we have focused on understanding the atmospheric circulation response to tropical SST forcing, the teleconnections discussed here can impact on surface climate (e.g., Flournoy et al. 2016; Goss et al. 2016; Graversen and Burtu 2016). Indeed, D14 showed that the positive geopotential height anomaly over NCG in their study resulted in enhanced surface warming. We find a similar result in that with the negative geopotential height anomaly there is a negative temperature anomaly at the surface (not shown). Therefore having a better understanding of what drives these circulation anomalies will improve understanding of surface climate drivers in a region that is already highly vulnerable to rapid global climate change (Hartmann et al. 2013; Cohen et al. 2014). 
Acknowledgments. This study was funded as part of the Natural Environment Research Council (NERC) studentship NE/L501633/1 with model simulations run using the ARCHER U.K. national supercomputer facility and data analysed using Python-Iris (https:// scitools.org.uk/iris/docs/latest/) on the JASMIN national data analysis platform. JSH acknowledges the NERC British Antarctic Survey's Polar Science for Planet Earth (PSPE) research programme, and the NERC "The North Atlantic Climate System Integrated Study" (ACSIS) project (Grant NE/N018028/1). ACM acknowledges support from an AXA Research Fund Postdoctoral Fellowship, a NERC Independent Research Fellowship (Grant NE/M018199/1), and the European Research Council ACCI project (Grant 267760). We would also like to thank Dr N. L. Abraham and Dr J. Pope for their help in setting up the HadGEM3-A simulations. We are grateful to Qinghua Ding and two anonymous reviewers whose suggestions led to significant improvements in the manuscript.

\section{REFERENCES}

Bindoff, N. L., and Coauthors, 2013: Detection and attribution of climate change: From global to regional. Climate Change 2013: The Physical Science Basis, T. F. Stocker et al., Eds., Cambridge University Press, 867-952, https://doi.org/ 10.1017/CBO9781107415324.022.

Bintanja, R., and E. C. van der Linden, 2013: The changing seasonal climate in the Arctic. Sci. Rep., 3, 1556, https://doi.org/ 10.1038/srep01556

_ , R. G. Graversen, and W. Hazeleger, 2011: Arctic winter warming amplified by the thermal inversion and consequent low infrared cooling to space. Nat. Geosci., 4, 758-761, https:// doi.org/10.1038/ngeo1285.

Breider, T. J., and Coauthors, 2017: Multidecadal trends in aerosol radiative forcing over the Arctic: Contribution of changes in anthropogenic aerosol to Arctic warming since 1980 J. Geophys. Res. Atmos., 122, 3573-3594, https://doi.org/10.1002/ 2016JD025321.

Cai, M., 2005: Dynamical amplification of polar warming. Geophys. Res. Lett., 32, L22710, https://doi.org/10.1029/ 2005 GL024481.

Cai, W., and Coauthors, 2019: Pantropical climate interactions. Science, 363, eaav4236, https://doi.org/10.1126/science.aav4236.

Cao, Y., S. Liang, X. Chen, T. He, D. Wang, and X. Cheng, 2017 Enhanced wintertime greenhouse effect reinforcing Arctic amplification and initial sea-ice melting. Sci. Rep., 7, 8462 , https://doi.org/10.1038/s41598-017-08545-2.

Castruccio, F. S., Y. Ruprich-Robert, S. G. Yeager, G. Danabasoglu, R. Msadek, and T. L. Delworth, 2019: Modulation of Arctic sea ice loss by atmospheric teleconnections from Atlantic multidecadal variability. J. Climate, 32, 1419-1441, https://doi.org/ 10.1175/JCLI-D-18-0307.1.

Chemke, R., and L. M. Polvani, 2020: Linking midlatitudes eddy heat flux trends and polar amplification. npj Climate Atmos. Sci., 3, 8, https://doi.org/10.1038/s41612-020-0111-7.

Chikamoto, Y., T. Mochizuki, A. Timmermann, M. Kimoto, and M. Watanabe, 2016: Potential tropical Atlantic impacts on
Pacific decadal climate trends. Geophys. Res. Lett., 43, 71437151, https://doi.org/10.1002/2016GL069544.

Chung, C. E., and P. Räisänen, 2011: Origin of the Arctic warming in climate models. Geophys. Res. Lett., 38, L21704, https:// doi.org/10.1029/2011GL049816.

Chylek, P., C. K. Folland, G. Lesins, M. K. Dubey, and M. Wang, 2009: Arctic air temperature change amplification and the Atlantic Multidecadal Oscillation. Geophys. Res. Lett., 36, L14801, https://doi.org/10.1029/2009GL038777.

Cionni, I., and Coauthors, 2011: Ozone database in support of CMIP5 simulations: Results and corresponding radiative forcing. Atmos. Chem. Phys., 11, 11 267-11 292, https://doi.org/ 10.5194/acp-11-11267-2011.

Coats, S., and K. B. Karnauskas, 2017: Are simulated and observed twentieth century tropical Pacific sea surface temperature trends significant relative to internal variability? Geophys. Res. Lett., 44, 9928-9937, https://doi.org/10.1002/ 2017GL074622.

Cohen, J., and Coauthors, 2014: Recent Arctic amplification and extreme mid-latitude weather. Nat. Geosci., 7, 627-637, https:// doi.org/10.1038/ngeo2234.

Davini, P., J. von Hardenberg, and S. Corti, 2015: Tropical origin for the impacts of the Atlantic multidecadal variability on the Euro-Atlantic climate. Environ. Res. Lett., 10, 094010, https:// doi.org/10.1088/1748-9326/10/9/094010.

Dee, D. P., and Coauthors, 2011: The ERA-Interim reanalysis: Configuration and performance of the data assimilation system. Quart. J. Roy. Meteor. Soc., 137, 553-597, https://doi.org/ 10.1002/qj.828.

Ding, Q., B. Wang, J. M. Wallace, and G. Branstator, 2011: Tropical-extratropical teleconnections in boreal summer: Observed interannual variability. J. Climate, 24, 1878-1896, https://doi.org/10.1175/2011JCLI3621.1.

_ J. M. Wallace, D. S. Battisti, E. J. Steig, A. J. E. Gallant, H.-J. Kim, and L. Geng, 2014: Tropical forcing of the recent rapid Arctic warming in northeastern Canada and Greenland. Nature, 509, 209-212, https://doi.org/10.1038/nature13260.

Ding, S., W. Chen, H. F. Graf, Y. Guo, and D. Nath, 2018: Distinct winter patterns of tropical Pacific convection anomaly and the associated extratropical wave trains in the Northern Hemisphere. Climate Dyn., 51, 2003-2022, https://doi.org/ 10.1007/s00382-017-3995-0.

Elsbury, D., Y. Peings, D. Saint-Martin, H. Douville, and G. Magnusdottir, 2019: The atmospheric response to positive IPV, positive AMV, and their combination in boreal winter. J. Climate, 32, 4193-4213, https://doi.org/10.1175/JCLI-D-180422.1.

Ferranti, L., F. Molteni, and T. N. Palmer, 1994: Impact of localized tropical and extratropical SST anomalies in ensembles of seasonal GCM integrations. Quart. J. Roy. Meteor. Soc., 120, 1613-1645, https://doi.org/10.1002/qj.49712052009.

Flournoy, M. D., S. B. Feldstein, S. Lee, and E. E. Clothiaux, 2016: Exploring the tropically excited Arctic warming mechanism with station data: Links between tropical convection and Arctic downward infrared radiation. J. Atmos. Sci., 73, 11431158, https://doi.org/10.1175/JAS-D-14-0271.1.

Freitas, A. C. V., and T. Ambrizzi, 2012: Changes in the austral winter Hadley circulation and the impact on stationary Rossby waves propagation. Adv. Meteor., 2012, 980816, https://doi.org/ 10.1155/2012/980816

, J. S. Frederiksen, T. J. O'Kane, and T. Ambrizzi, 2017: Simulated austral winter response of the Hadley circulation and stationary Rossby wave propagation to a warming 
climate. Climate Dyn., 49, 521-545, https://doi.org/10.1007/ s00382-016-3356-4.

Gill, A. E., 1980: Some simple solutions for heat-induced tropical circulation. Quart. J. Roy. Meteor. Soc., 106, 447-462, https:// doi.org/10.1002/qj.49710644905.

Gimeno, L., M. Vázquez, R. Nieto, and R. M. Trigo, 2015: Atmospheric moisture transport: The bridge between ocean evaporation and Arctic ice melting. Earth Syst. Dyn., 6, 583589, https://doi.org/10.5194/esd-6-583-2015.

Gong, T., S. Feldstein, and S. Lee, 2017: The role of downward infrared radiation in the recent Arctic winter warming trend. J. Climate, 30, 4937-4949, https://doi.org/10.1175/JCLI-D-160180.1 .

Goosse, H., and Coauthors, 2018: Quantifying climate feedbacks in polar regions. Nat. Commun., 9, 1919, https://doi.org/10.1038/ s41467-018-04173-0.

Goss, M., S. B. Feldstein, and S. Lee, 2016: Stationary wave interference and its relation to tropical convection and Arctic warming. J. Climate, 29, 1369-1389, https://doi.org/10.1175/ JCLI-D-15-0267.1.

Graversen, R. G., and M. Wang, 2009: Polar amplification in a coupled climate model with locked albedo. Climate Dyn., 33, 629-643, https://doi.org/10.1007/s00382-009-0535-6.

—, and M. Burtu, 2016: Arctic amplification enhanced by latent energy transport of atmospheric planetary waves. Quart. J. Roy. Meteor. Soc., 142, 2046-2054, https://doi.org/10.1002/ qj. 2802.

, T. Mauritsen, M. Tjernström, E. Källén, and G. Svensson, 2008: Vertical structure of recent Arctic warming. Nature, 451, 53-56, https://doi.org/10.1038/nature06502.

Hanna, E., and Coauthors, 2014: Atmospheric and oceanic climate forcing of the exceptional Greenland ice sheet surface melt in summer 2012. Int. J. Climatol., 34, 1022-1037, https://doi.org/ 10.1002/joc.3743.

Hartmann, D. L., and Coauthors, 2013: Observations: Atmosphere and surface. Climate Change 2013: The Physical Science Basis, T. F. Stocker et al., Eds., Cambridge University Press, 159254.

Hewitt, H. T., D. Copsey, I. D. Culverwell, C. M. Harris, R. S. R. Hill, A. B. Keen, A. J. McLaren, and E. C. Hunke, 2011: Design and implementation of the infrastructure of HadGEM3: The next-generation Met Office climate modelling system. Geosci. Model Dev., 4, 223-253, https://doi.org/10.5194/gmd-4223-2011.

Hoskins, B. J., and D. J. Karoly, 1981: The steady linear response of a spherical atmosphere to thermal and orographic forcing. J. Atmos. Sci., 38, 1179-1196, https://doi.org/10.1175/15200469(1981)038<1179:TSLROA > 2.0.CO;2.

Hurrell, J. W., J. J. Hack, D. Shea, J. M. Caron, and J. Rosinski, 2008: A new sea surface temperature and sea ice boundary dataset for the Community Atmosphere Model. J. Climate, 21, 5145-5153, https://doi.org/10.1175/2008JCLI2292.1.

Ineson, S., and A. A. Scaife, 2009: The role of the stratosphere in the European climate response to El Niño. Nat. Geosci., 2, 3236, https://doi.org/10.1038/ngeo381.

Jin, F., and B. Hoskins, 1995: The direct response to tropical heating in a baroclinic atmosphere. J. Atmos. Sci., 3, 307-319, https://doi.org/10.1175/1520-0469(1995)052<0307:TDRTTH> 2.0.CO;2.

Kattsov, V. M., and J. E. Walsh, 2000: Twentieth-century trends of Arctic precipitation from observational data and a climate model simulation. J. Climate, 13, 1362-1370, https://doi.org/ 10.1175/1520-0442(2000)013<1362:TCTOAP > 2.0.CO;2.
Kosaka, Y., and S. P. Xie, 2013: Recent global-warming hiatus tied to equatorial Pacific surface cooling. Nature, 501, 403-407, https://doi.org/10.1038/nature12534.

Kucharski, F., F. S. Syed, A. Burhan, I. Farah, and A. Gohar, 2014: Tropical Atlantic influence on Pacific variability and mean state in the twentieth century in observations and CMIP5. Climate Dyn., 44, 881-896, https://doi.org/10.1007/s00382-014-2228-z.

Langen, P. L., and V. A. Alexeev, 2007: Polar amplification as a preferred response in an idealized aquaplanet GCM. Climate Dyn., 29, 305-317, https://doi.org/10.1007/s00382-006-0221-x.

Lau, N.-C., and M. J. Nath, 1994: A modelling study of the relative roles of tropical and extratropical SST anomalies in the variability of the global atmosphere-ocean system. J. Climate, $\mathbf{7}$, 1184-1207, https://doi.org/10.1175/1520-0442(1994)007<1184: AMSOTR $>2.0 . \mathrm{CO} ; 2$.

Lee, S., 2012: Testing of the tropically excited Arctic warming mechanism (TEAM) with traditional El Niño and La Niña. J. Climate, 25, 4015-4022, https://doi.org/10.1175/JCLI-D-1200055.1.

, T. Gong, S. B. Feldstein, J. A. Screen, and I. Simmonds, 2017: Revisiting the cause of the 1989-2009 Arctic surface warming using the surface energy budget: Downward infrared radiation dominates the surface fluxes. Geophys. Res. Lett., 44, 10654 10 661, https://doi.org/10.1002/2017gl075375.

Lesins, G., T. J. Duck, and J. R. Drummond, 2012: Surface energy balance framework for Arctic amplification of climate change. J. Climate, 25, 8277-8288, https://doi.org/10.1175/JCLI-D-1100711.1.

Li, X., S.-P. Xie, S. T. Gille, and C. Yoo, 2015: Atlantic-induced pan-tropical climate change over the past three decades. Nat. Climate Change, 6, 275-279, https://doi.org/10.1038/ nclimate2840.

Mahajan, S., R. Zhang, and T. L. Delworth, 2011: Impact of the Atlantic meridional overturning circulation (AMOC) on Arctic surface air temperature and sea ice variability. J. Climate, $\mathbf{2 4}$, 6573-6581, https://doi.org/10.1175/2011JCLI4002.1.

McGregor, S., A. Timmermann, M. F. Stuecker, M. H. England, M. Merrifield, F. F. Jin, and Y. Chikamoto, 2014: Recent Walker circulation strengthening and Pacific cooling amplified by Atlantic warming. Nat. Climate Change, 4, 888-892, https:// doi.org/10.1038/nclimate2330.

Meehl, G. A., C. T. Chung, J. M. Arblaster, M. M. Holland, and C. M. Bitz, 2018: Tropical decadal variability and the rate of Arctic sea ice decrease. Geophys. Res. Lett., 45, 11326-11333, https://doi.org/10.1029/2018GL079989.

Niebauer, H. J., 1988: Effects of El Niño-Southern Oscillation and North Pacific weather patterns on interannual variability in the subarctic Bering Sea. J. Geophys. Res., 93, 5051-5068, https://doi.org/10.1029/JC093iC05p05051.

O'Kane, T. J., J. S. Risbey, D. P. Monselesan, I. Horenko, and C. L. Franzke, 2016: On the dynamics of persistent states and their secular trends in the waveguides of the Southern Hemisphere troposphere. Climate Dyn., 46, 3567-3597, https://doi.org/ 10.1007/s00382-015-2786-8.

Okumura, Y. M., C. Deser, A. Hu, A. Timmermann, and S.-P. Xie, 2009: North Pacific climate response to freshwater forcing in the subarctic North Atlantic: Oceanic and atmospheric pathways. J. Climate, 22, 1424-1445, https://doi.org/10.1175/ 2008JCLI2511.1.

O'Reilly, C. H., T. Woollings, L. Zanna, and A. Weisheimer, 2018: The impact of tropical precipitation on summertime EuroAtlantic circulation via a circumglobal wave train. J. Climate, 31, 6481-6504, https://doi.org/10.1175/JCLI-D-17-0451.1. 
,,--- , and $-, 2019:$ An interdecadal shift of the extratropical teleconnection from the tropical Pacific during boreal summer. Geophys. Res. Lett., 46, 13 379-13 388, https:// doi.org/10.1029/2019GL084079.

Peings, Y., and G. Magnusdottir, 2014: Forcing of the wintertime atmospheric circulation by the multidecadal fluctuations of the North Atlantic Ocean. Environ. Res. Lett., 9, 034018, https:// doi.org/10.1088/1748-9326/9/3/034018.

Pithan, F., and T. Mauritsen, 2014: Arctic amplification dominated by temperature feedbacks in contemporary climate models. Nat. Geosci., 7, 181-184, https://doi.org/10.1038/ngeo2071.

Plumb, R. A., 1985: On the three-dimensional propagation of stationary waves. J. Atmos. Sci., 42, 217-229, https://doi.org/ 10.1175/1520-0469(1985)042<0217:OTTDPO > 2.0.CO;2.

Rayner, N. A., D. E. Parker, E. B. Horton, C. Folland, L. Alexander, D. Rowell, E. Kent, and A. Kaplan, 2003: Global analyses of sea surface temperature, sea ice, and night marine air temperature since the late nineteenth century. J. Geophys. Res., 108, 4407, https://doi.org/10.1029/2002JD002670.

Rodionov, S. N., N. A. Bond, and J. E. Overland, 2007: The Aleutian low, storm tracks, and winter climate variability in the Bering Sea. Deep-Sea Res. II, 54, 2560-2577, https:// doi.org/10.1016/j.dsr2.2007.08.002.

Ruprich-Robert, Y., R. Msadek, F. Castruccio, S. Yeager, T. Delworth, and G. Danabasoglu, 2017: Assessing the climate impacts of the observed Atlantic multidecadal variability using the GFDL CM2.1 and NCAR CESM1 global coupled models. J. Climate, 30, 2785-2810, https://doi.org/10.1175/JCLI-D-16-0127.1.

Sardeshmukh, P., and B. Hoskins, 1988: The generation of global rotational flow by steady idealized tropical divergence. J. Atmos. Sci., 45, 1228-1251, https://doi.org/10.1175/15200469(1988)045<1228:TGOGRF $>2.0$. CO;2.

Scaife, A. A., and Coauthors, 2017: Tropical rainfall, Rossby waves and regional winter climate predictions. Quart. J. Roy. Meteor. Soc., 143, 1-11, https://doi.org/10.1002/qj.2910.

Screen, J. A., and I. Simmonds, 2010a: Increasing fall-winter energy loss from the Arctic Ocean and its role in Arctic temperature amplification. Geophys. Res. Lett., 37, L16707, https://doi.org/ 10.1029/2010GL044136.

_ and , 2010b: The central role of diminishing sea ice in recent Arctic temperature amplification. Nature, 464, 1334 1337, https://doi.org/10.1038/nature09051.

— , and J. A. Francis, 2016: Contribution of sea-ice loss to Arctic amplification is regulated by Pacific Ocean decadal variability. Nat. Climate Change, 6, 856-860, https://doi.org/10.1038/nclimate3011.

_ I. Simmonds, C. Deser, and R. Tomas, 2013: The atmospheric response to three decades of observed Arctic sea ice loss. J. Climate, 26, 1230-1248, https://doi.org/10.1175/JCLI-D-12-00063.1.

Serreze, M. C., and J. C. Stroeve, 2015: Arctic sea ice trends, variability and implications for seasonal ice forecasting. Philos. Trans. Roy. Soc. London, A373, 20140159, https://doi.org/10.1098/RSTA.2014.0159.

_ - A. Barrett, and J. Stroeve, 2009: The emergence of surfacebased Arctic amplification. Cryosphere, 3, 11-19, https:// doi.org/10.5194/tc-3-11-2009.

Shepherd, A., and Coauthors, 2019: Mass balance of the Greenland Ice Sheet from 1992 to 2018. Nature, 579, 233-239, https:// doi.org/10.1038/s41586-019-1855-2.

Sheridan, S., and C. C. Lee, 2012: Synoptic climatology and the analysis of atmospheric teleconnections. Prog. Phys. Geogr., 36, 548-557, https://doi.org/10.1177/0309133312447935.

Shimizu, M. H., and I. F. de Albuquerque Cavalcanti, 2010: Variability patterns of Rossby wave source. Climate Dyn., 37, 441-454, https://doi.org/10.1007/s00382-010-0841-z.
Simpkins, G. R., L. M. Ciasto, D. W. J. Thompson, and M. H. England, 2012: Seasonal relationships between large-scale climate variability and Antarctic sea ice concentration. J. Climate, 25, 5451-5469, https://doi.org/10.1175/JCLI-D-1100367.1.

- S. McGregor, A. S. Taschetto, L. M. Ciasto, and M. H. England, 2014: Tropical connections to climatic change in the extratropical Southern Hemisphere: The role of Atlantic SST trends. J. Climate, 27, 4923-4936, https://doi.org/10.1175/JCLID-13-00615.1.

Sun, C., F. Kucharski, J. Li, F.-F. Jin, I.-S. Kang, and R. Ding, 2017: Western tropical Pacific multidecadal variability forced by the Atlantic multidecadal oscillation. Nat. Commun., 8, 15998, https://doi.org/10.1038/ncomms15998.

Sutton, R. T., and D. L. R. Hodson, 2007: Climate response to basin-scale warming and cooling of the North Atlantic Ocean. J. Climate, 20, 891-907, https://doi.org/10.1175/ JCLI4038.1.

Svendsen, L., N. Keenlyside, I. Bethke, Y. Gao, and N.-E. Omrani, 2018: Pacific contribution to the early twentieth-century warming in the Arctic. Nat. Climate Change, 8, 793-797, https://doi.org/10.1038/s41558-018-0247-1.

Tokinaga, H., S.-P. Xie, and H. Mukougawa, 2017: Early 20thcentury Arctic warming intensified by Pacific and Atlantic multidecadal variability. Proc. Natl. Acad. Sci. USA, 114, 6227-6232, https://doi.org/10.1073/pnas.1615880114.

Trascasa-Castro, P., A. C. Maycock, Y. Y. Scott Yiu, and J. K. Fletcher, 2019: On the linearity of the stratospheric and EuroAtlantic sector response to ENSO. J. Climate, 32, 6607-6626, https://doi.org/10.1175/JCLI-D-18-0746.1.

Trenberth, K. E., G. W. Branstator, D. Karoly, A. Kumar, N.-C. Lau, and C. Ropelewski, 1998: Progress during TOGA in understanding and modeling global teleconnections associated with tropical sea surface temperatures. J. Geophys. Res., 103, 14 291-14 324, https://doi.org/10.1029/97JC01444.

, J. T. Fasullo, G. Branstator, and A. S. Phillips, 2014: Seasonal aspects of the recent pause in surface warming. Nat. Climate Change, 4, 911-916, https://doi.org/10.1038/nclimate2341.

Tyrrell, G. C., D. J. Karoly, J. L. McBride, D. J. Karoly, and J. L. McBride, 1996: Links between tropical convection and variations of the extratropical circulation during TOGA COARE. J. Atmos. Sci., 53, 2735-2748, https://doi.org/10.1175/15200469(1996)053<2735:LBTCAV > 2.0.CO;2.

Walsh, J. E., J. E. Overland, P. Ya. Groisman, and B. Rudolf, 2011: Ongoing climate change in the Arctic. Ambio, 40, 6-16, https:// doi.org/10.1007/s13280-011-0211-z.

Wegmann, M., S. Brönnimann, and G. P. Compo, 2017: Tropospheric circulation during the early twentieth century Arctic warming. Climate Dyn., 48, 2405-2418, https://doi.org/10.1007/s00382016-3212-6.

Yoshimori, M., A. Abe-Ouchi, and A. Laîné, 2017: The role of atmospheric heat transport and regional feedbacks in the Arctic warming at equilibrium. Climate Dyn., 49, 3457-3472, https://doi.org/10.1007/s00382-017-3523-2.

Zhang, C., J. Luo, and S. Li, 2019: Impacts of tropical Indian and Atlantic Ocean warming on the occurrence of the 2017/2018 La Niña. Geophys. Res. Lett., 46, 3435-3445, https://doi.org/ 10.1029/2019GL082280.

Zhang, R., and T. L. Delworth, 2007: Impact of the Atlantic multidecadal oscillation on North Pacific climate variability. Geophys. Res. Lett., 34, L23708, https://doi.org/10.1029/ 2007 GL031601. 